IZA DP No. 7037

The Cost of Acting "Girly":

Gender Stereotypes and Educational Choices

Marta Favara

November 2012 


\title{
The Cost of Acting "Girly": Gender Stereotypes and Educational Choices
}

\author{
Marta Favara \\ ISER, University of Essex \\ and IZA
}

\author{
Discussion Paper No. 7037 \\ November 2012
}

\author{
IZA \\ P.O. Box 7240 \\ 53072 Bonn \\ Germany \\ Phone: +49-228-3894-0 \\ Fax: +49-228-3894-180 \\ E-mail: iza@iza.org
}

Any opinions expressed here are those of the author(s) and not those of IZA. Research published in this series may include views on policy, but the institute itself takes no institutional policy positions. The IZA research network is committed to the IZA Guiding Principles of Research Integrity.

The Institute for the Study of Labor (IZA) in Bonn is a local and virtual international research center and a place of communication between science, politics and business. IZA is an independent nonprofit organization supported by Deutsche Post Foundation. The center is associated with the University of Bonn and offers a stimulating research environment through its international network, workshops and conferences, data service, project support, research visits and doctoral program. IZA engages in (i) original and internationally competitive research in all fields of labor economics, (ii) development of policy concepts, and (iii) dissemination of research results and concepts to the interested public.

IZA Discussion Papers often represent preliminary work and are circulated to encourage discussion. Citation of such a paper should account for its provisional character. A revised version may be available directly from the author. 


\section{ABSTRACT \\ The Cost of Acting "Girly": Gender Stereotypes and Educational Choices}

This paper looks at horizontal sex segregation in education as a factor contributing to gender segregation in the labor market. Economic theories fail to explain why women with the same years of schooling and educational attainment as men are under-represented in many technical degrees, which typically lead to better paid occupations. Following Akerlof and Kranton (2000), I research whether gender identity affects boys' and girls' educational choices and when the gendered pattern appears first. Further, I test the hypothesis that single-sex schools attenuate the influence of gender-stereotypes. I use the National Pupil Database, which is a register of all pupils enrolled in state maintained schools in England and I focus on students in lower and upper secondary education. Results from my analysis suggest that gender stereotyping affects educational choices from the age of 14 and this effect is larger for girls than for boys. I also find that attending a sixth-form-single-sex school leads students to a less stereotyped educational choice, after controlling for endogenous selfselection into single-sex schools. This suggests that gender preferences can be modified by the environment.

JEL Classification: $\quad$ I2, J16, J24

Keywords: $\quad$ gender segregation, educational choices, gender stereotypes, single-sex schools

Corresponding author:

Marta Favara

Institute for Social \& Economic Research (ISER)

University of Essex

Wivenhoe Park

Colchester, Essex CO4 3SQ

United Kingdom

E-mail:mfavar@essex.ac.uk

\footnotetext{
*I would like to thank Cheti Nicoletti and Mark Bryan for the extensive discussion, Lidia Farre, Matthew J. Lindquist, Shelly Lundberg, Tuomas Pekkarinen, Steve Pudney, Anders Stenberg, for their valuable comments and the participants at SOFI seminar 2012, Stockholm; ESPE 2012, Bern, CESifo 2012, Munich; EALE 2011, Paphos; BSPS Conference 2011, York; EEA 2011, Oslo; 4th Italian Doctoral Workshop in Economics and Policy Analysis, Turin; IZA Summer School, Munich, COSME-FEDEA 2011, Barcelona for their helpful suggestions. An earlier version of this paper has been awarded as best paper in gender economics in the second editionof the UWIN Best Paper Award competition, launched by UniCredit \& Universities Foundationin cooperation with UniCredit Womens International Network (UWIN). All mistakes are the author's only responsibility.
} 


\section{Introduction}

Even if there are no substantial gender-based differences in the "quantity" of education (e.g. years of schooling, secondary and post-secondary school attendance), the opposite is true for the "content" of education received. Empirical evidence shows that in most European countries women are under-represented in many technical degrees, e.g. Engineering and Science, whereas they are over-represented in Humanities, Languages, Education and the Arts (Turner and Bowen, 1999).

The horizontal sex segregation in education might be a factor contributing to gender segregation in the labour market given that the content of schooling accounts for a substantial part of the gender gap in earnings (Brown and Corcoran, 1997; Arcidiacono, 2004). ${ }^{1}$ Certain subjects, and more often stereotypically male subjects, generate a higher monetary return and create more valuable job-related human capital.

The reason why girls do not choose the most rewarding majors in terms of future wage and labour market opportunities is still debatable. Empirical evidence shows that frequently girls outperform boys in male-dominant subjects. Thus, gender-based differences in abilities cannot explain differences in educational choices. One possibility is that gender discrimination in the labour market generates sex-differences in subject choice. Female students anticipate potential gender discrimination in the labour market avoiding those majors which offer higher rewards for men than for women. Alternatively, experimental evidence suggests that the gender gap in the choice of the college major is mainly due to differences in non-pecuniary preferences and tastes (Zafar, 2009). Economic incentives are not sufficient for girls to enroll and stay more in male traditional fields of study (Noè, 2010).

My paper strongly relies on Akerlof and Kranton's (2000) theoretical approach and it relates to the economic literature studying the role of social identity in determining individual behaviours and gender differences in economic outcomes (Chen and Li, 2009; Benjamin et al., 2010; Delavande and Zafar, 2011). I integrate the concept of gender

\footnotetext{
${ }^{1}$ Similar to the concept used for occupational segregation, horizontal segregation in education refers to differences in the proportion of female and male students across fields of study with the over-representation of one gender over the other one.
} 
identity into an economic model of educational choices, to test the hypothesis that students' preferences are shaped by notions of gender identity congruence. Students choose their subject specialization according to both their expected monetary returns and the pay-offs in terms of identity. If a student conforms to the social norms of the reference group, here identified by gender, she receives an indirect utility ("non-pecuniary pay-off") due to a more rewarding self-image. Conversely, violating the prescriptions of gender identity generates a loss of utility.

I model students' educational choice as a function of previous attainments to investigate whether students follow their talents and how sex-roles affect their choices. In particular, I investigate how students' choice departs from the educational path maximizing the expected monetary pay-off which is often associated with male segregated careers. Girls might decide not to enroll in stereotypically male careers to avoid the contravention of a social norm and the subsequent social stigma resulting in a disutility. The presence of a non-pecuniary pay-off explains a choice which otherwise might be considered as irrational because it is detrimental for future labour opportunities.

Using the National Pupil Database $(N P D)$, a register of all pupils in state maintained schools in England, I look at the relationship between grades and subject choice during compulsory (14-16 years old) and post-compulsory secondary education (16-18 years old). ${ }^{2}$ More specifically, I investigate (i) whether girls and boys follow gender-stereotyped trajectories in education; (ii) whether single-sex schools attenuate the influence of genderstereotypes and educational sex segregation and (iii) when gender stereotypes start affecting educational choices.

Results from my analysis suggest that gender traits affect educational choice. Indeed, both girls and boys make gender stereotyped choices. The influence of gender roles is particularly prominent for girls and it affects their educational choices as early as the beginning of secondary education, around age 14. I find that there is a gendered subject specialization which cannot be explained by gender-specific abilities. In particular girls are more likely to choose educational options usually associated with lower pecuniary pay-offs to conform to their gender stereotypes. Finally, my results suggests that gender

\footnotetext{
2I will use the words "grade" and "attainment" interchangeably.
} 
traits can be modified by the environment, consistent with experimental literature (Booth et al., 2011). Indeed, single-sex schools attenuate the influence of gender stereotypes for girls and the opposite for boys.

This paper extends previous literature in various ways. Most previous empirical works investigating how gender norms affect economic decisions, use experimental data. The empirical strategy adopted in the present analysis identifies the role of gender identity on student choice with no experimental data. The advantage of using the $N P D$ is that it includes the whole population of students in the state public educational system in England. Additionally, the longitudinal setting allows for the identification of when gender stereotypes start affecting educational choices, comparing the curriculum choice at 16-18 years old with the choice at 14-16 years old.

The present analysis exploits the unique heterogeneity in students' choices due to the broad range of elective subjects provided by the UK education system. I derive an indicator which captures the heterogeneity of students' syllabus composition and varies between 0 and 1 , with 1 corresponding to a male stereotyped choice and 0 to a female stereotyped choice. The main advantage is that it allows me to study the presence of gender gap in educational choice considering the entire syllabus composition and avoiding arbitrary definition of gender stereotyped choices.

Finally, I add to the literature on single sex schooling by analysing the effect of singlesex schools on educational choices rather than on attainments and cognitive test scores (Park et al., 2012; Jackson, 2011; Mael et al., 2005). Furthermore, I move beyond the associations that dominate the existing literature on single-sex schools to draw causal inferences about the effect of single-sex environment on students' choices by using an endogenous switching model which corrects for potential biases due to non-random selection into single-sex schools. 


\section{Previous Literature on Identity and Gender Seg- regation in Educational Choices}

\subsection{Why do Girls and Boys make different choices? Gender Identity and Conforming Choices}

Empirical evidence suggests that gender gaps persist in terms of choice of major. Research in Psychology and Medicine has explained gender segregation by the presence of biological and neurological gender differences. According to this approach, boys use more cortical areas dedicated to spatial and mechanical functioning (Kimura, 2000). Conversely, girls develop more the part of the brain devoted to verbal and emotional functioning. For this reason, girls may underperform relatively in technical and quantitative subjects from childhood and gradually disengage from these subjects (Killgore and Yurgelun-Todd, 2004; Lenroot, et al. 2007).

More recently, the economic literature focusing on decision-making process, emphasizes the important role of preferences and social interactions in explaining how individuals make decisions. Part of this literature studies the structure of social groups and shows a tendency of individuals to interact with others with similar characteristics (Marsden, 1988; Akerlof, 1997) and make conforming choices (Cooley, 2006; Sacerdote, 2001). Thus, because of social interactions individual decisions are not independent (Manski, 2000).

Zafar (2011) offers an interesting classification of why individuals conform. They conform to the choice of others because they consider that if others made this choice it might be a signal about the goodness of this choice (social learning). Alternatively, they might conform because if they do not stick to the norm they might experience a disutility related to self-image concerns (social influence). Image-related concerns arise only if the individual actions are observable to other people. The extent of fear of receiving a social sanction affects the individual behaviour differs from individual to individual and presumably across different social groups. Finally, individuals might conform simply because making the same choice as their peers generates a positive utility gain even when their identities are hidden (social comparison)(Cialdini, 1993). 
Akerlof and Kranton (2000 and 2002) argue that individuals assimilate behaviours and characteristics of the social category they belong to. These behaviours and characteristics define the group's social identity. ${ }^{3}$ Individuals obtain a gain in utility from conforming to the choice of their reference group and a loss otherwise (Akerlof and Kranton, 2000; Cont and Löwe, 2010). Akerlof and Kranton (2000) propose the following general utility function which incorporates identity into the standard economic models:

$$
U_{i}=U_{i}\left(\mathbf{a}_{i}, \mathbf{a}_{-i}, I_{i}\right)
$$

where $\mathbf{a}_{i}$ is the vector of actions of individual $i, \mathbf{a}_{-i}$ is the vector of actions of all other individuals, and $I_{i}$ is the self-image of individual $i$. The self-image component depends on $\mathbf{a}_{i}, \mathbf{a}_{-i}$, a vector of individual exogenous characteristics $\epsilon_{i}$, the assignment of individual $i$ to the social category $\mathbf{c}_{i}$ and to the prescriptions attached to that social category, $\mathbf{P}:{ }^{4}$

$$
\mathrm{I}_{i}=I_{i}\left(\mathbf{a}_{i}, \mathbf{a}_{-i} ; \mathbf{c}_{i}, \boldsymbol{\epsilon}_{\boldsymbol{i}}, \mathbf{P}\right)
$$

Under normal circumstances, each person has full control of her own actions, but cannot change the prescriptions of her social category on her own. Society determines the norms and ideal behaviours attached to each social category. Arkelof and Kranton (2000) argue that "everyone in the population is assigned a gender category, as either a 'man' or a 'woman'. Following the behavioural prescriptions for one's gender affirms one's self-image or identity, as a 'man' or as a 'woman'" (Akerlof and Kranton, 2000, pag. 716-7). Any deviation from the ideal characteristics and the ideal behaviour for that social category causes a breach in social norms and generates a sense of guilt and uncertainty. This loss of utility may convince the person to conform (Levine, 1989; Turner, 1991).

The formation of the self-identity is a gradual process from childhood through adolescence (Bénabou and Tirole, 2011). Individuals have an initial endowment of self-identity and prior beliefs and information determined by the social environment. The belief about "what kind of a person one is" is more dynamic during adolescence when the idea of

\footnotetext{
${ }^{3}$ The concept of social identity was first developed by Tajfel and Turner (1979).

${ }^{4}$ Akerlof and Kranton define prescriptions as "the behavior appropriate for people in different social categories in different situations" and also as "an ideal for each category in terms of physical characteristics and other attributes" (Akerlof and Kranton, 2000, pag. 718).
} 
"self" is still in development. Staw (1976) highlights the importance of beliefs and gender stereotypes assimilated during childhood which affects further investments in gender identity during adulthood.

The return deriving from identifying with a specific group is subject to change mainly for two reasons. First, the marginal utility of conforming to the social norms of the group (or the stigma caused by a breach of the group's norms) is different when the individual first joins the group to when she is an established member. Second, individuals' preferences might change. Indeed, they gain better knowledge of their preferences through experience and by social context or interactions (Grotevant, 1987).

\subsection{In What Ways Do Male and Female Stereotypes differ? Self- confidence, Attitude to Competition and Risk Preferences}

The most prominent definition of social category is by gender, which naturally divides society into two subgroups. Gender specific attributes such as risk aversion, self-confidence and attitude to competition contribute to sketch the gender identity. These attributes develop during childhood and affect boys' and girls' choices along their lifecycles (Sutter and Rützler, 2010; Gneezy and Rustichini, 2004).

A wide literature documents that women are generally more risk averse than men and more likely to shy away from competition (Booth and Nolen, 2011; Croson and Gneezy, 2009; Gneezy et al., 2003; Niederle and Vesterlund, 2007 and 2010; Datta Gupta et al., 2005).

Furthermore, behavioural psychology suggests that girls are under-confident in their abilities with respect to boys (Niederle and Vesterlund, 2007; Streitmatter, 2002; Pomerantz et al., 2002). For example, Kurtz-Costes et al.(2008) suggest that girls' perception of their own Mathematics and Sciences abilities is lower than for boys. They speculate that female educational segregation arises from a process of self-efficacy adjustment, i.e. an adjustment of their beliefs in their own abilities. Generally, girls suffer low self-efficacy particularly on those subjects where they feel more competition from boys or where ob- 
taining high marks is relatively more difficult (Van de Werfhorst et al., 2003; Wilder and Powell, 1989).

In contrast, Zafar (2009), using unique experimental data of Northwestern University graduates, finds that gender differences in beliefs about ability cannot explain the gender gap in major choices. The same for gender differences in beliefs about future earnings associated with each major which are insignificant and explain less than 1 percent of the gender gap. Conversely, he finds that the main part of the gender gap can be explained by gender differences in tastes and preferences for studying different fields.

The gender specific attributes discussed above might explain why boys and girls have different educational preferences (Turner and Bowen, 1999). Differences in attitudes and preferences might affect the relative importance of pecuniary versus non-pecuniary benefits (Turner and Bowen, 1999).

Humlum et al. (2012), using Danish data, derive a model of career choice and identity. They characterize two identities relevant for educational choice: "career oriented" and "social oriented" typology. For a "career oriented" person, career and work are important for a meaningful life. Conversely "social oriented" persons assign "more importance to cooperation, social responsibility and social issues, such as other people's well-being" (Humlum et al., 2012, pag.14). They find that these two underlying factors vary systematically with the investments in level and field of education and they consider this result as evidence that identity pay-offs are an important part of educational decision making. According to their findings, students' educational choices are consistent with their self-images. Students with a "career oriented" identity, choose according to the financial incentive they believe is associated with their choice.

\subsection{Does the Single-Sex Environment Affect Gender Traits and Educational Choices?}

Several studies investigate the extent to which differences in educational choices among boys and girls might be due to innate gender traits or might be shaped by the environ- 
ment. Recently, interest has increased in the potential effect of single-sex environment on students' performance and educational choice.

There is no consensus on the effects of single-sex education and the main issue of disagreement concerns self-selection problems arising from the non-random assignment to single-sex schools. Differences in attainments and choices of students in single or mixed schools may reflect selection mechanisms rather than being the effect of the environment per se.

A growing literature shows that girls are more likely to choose male subjects and have higher attainment in them if they are in single-sex classes or in classes with a high share of female students (Mael et al., 2005; Billger, 2002; Rogers and Menaghan, 1991). Conversely, most of the studies do not find differences in attainments for male students with the exception of Haag (2000) and Stables (1990) who find that boys perform better in languages, reading and writing test in single-sex than in mixed schools.

Although many of the studies focus on gender differences in attainments, little evidence exists on how all-boys and all-girls school may influence educational choices. Tidball (1985 and 1986) finds that women in male fields in higher education disproportionately graduated from single-sex colleges. Similarly, Schneeweis and Zweimuller (2012), using Austrian data on students aged 14 years old and enrolled in compulsory schools, find that girls are more likely to choose a technical school if in previous grades they attended a school with a higher percentage of female students.

In England, where the tradition of single-sex schools is well established, the Institute of Education (IOE) have conducted a study on a large set of outcomes for students in single-sex and mixed schools. They use data from the National Child Development Study and the British Cohort Studies for two large cohorts of children, born in 1958 and 1970 (Joshi et al., 2010). This study shows that those who went to single-sex schools were more likely to study subjects not traditionally associated with their gender and to have more confidence in their ability to do well in these subjects. This study also find that at university women who went to girls' schools were more likely than co-educated women to gain qualifications in subjects typically dominated by men, and that both men and women from single-sex schools had a less sex-segregated experience of the labour market. 
In particular, single-sex schooling improves girls' chances of landing well-paid careers.

Proponents of single-sex schools believe that coeducational settings strengthen traditional gender role socialization and thus ultimately put girls off stereotypically male subjects. Conversely, in single-sex school girls are freer to explore their talents and gender roles fade away. The mechanisms through which this occurs are still under debate and many have been discussed in the last decades.

Booth and Nolen (2011 and 2012) use an experimental approach to show that the environment changes girls' attitude to competition and risk. ${ }^{5}$ According to their findings, girls from single-sex schools are more likely to enter competition than coeducational girls even when assigned to mixed-classes (2011) and that a single-sex environment changes risk preferences (2012). Similarly, Booth et al. (2011) find that female students randomly assigned to single-sex classes for two months are less risk averse that their counterparts in mixed classes. Conversely, they do not find any evidence of a change in behaviour for male students assigned to all-male or mixed classes. Their findings suggest that part of gender differences in educational choices reflects "social learning" and that gender traits can actually be modified.

Another hypothesis is that single-sex environment helps students to concentrate on academic learning. Coleman (1961) shows that students in mixed schools are concerned about appearance and popularity which distract them from their academic achievement. In particular, girls in mixed schools may worry about appearing "too clever" to attract boys (Riordan, 1990). In mixed schools girls perceive the dominance of boys while in single-sex schools they are no longer concerned about boys' reactions. For example, they participate more actively in the lessons not being afraid to ask or answer to teachers' questions (Streitmatter, 2002).

Furthermore, single-sex school dynamics might influence educational performance and choices through self-esteem and self-confidence. For example, Park et al. (2012) speculate that single-sex schools improve girls' academic achievement by enhancing their confidence

\footnotetext{
${ }^{5}$ Similarly to Both and Nolen (2011 and 2012), a number of experimental works test the hypothesis that social roles matter for individual's behavior by altering exogenously the salience of social identification (Benjamin et al., 2010; Chen and Li, 2009; Charness et al., 2007; Hoff and Pandey, 2006; Delavande and Zafar, 2011).
} 
in academic learning. They argue that the reason why this happens is because singlesex schools alleviate the competition with the other sex and the influence of adolescent culture.

Finally, some studies focus on the nature of interactions between students and teachers and how social norms affect not just the students but also the teachers' behavior. The first argument is that teachers treat boys and girls differently in coeducational settings. They tend to interact with and encourage boys more than girls, to take subjects such as Mathematics and Science (Lee et al., 1994; Oakes, 1990). The second argument concerns how students react to teachers of their own sex. Dee (2007) finds that both boys and girls have better educational achievement if the teacher is of the same sex. This might generate differences between mixed and single-sex schools if all-boys and all-girls schools tend to have more male and female teachers than mixed schools, respectively.

\section{Theoretical Framework}

The theoretical approach used in this paper relies on Akerlof and Kranton's models (2000 and 2002). There are two main features of this approach. Firstly, non-pecuniary preferences play a crucial role in the decision making process. Secondly, in making a decision individuals are influenced by other agents. For instance, when considering alternative choices, a female student takes into account the kind of person each alternative would "make her" and the desirability of those self-views. The "distance" between her behaviour and the ideal prescribed behaviour for girls is a measure of how much she conforms to the "girly" stereotype. The closer the matching, the higher is her non-pecuniary pay-off. ${ }^{6}$

Considering the general framework of utility and identity proposed by Akerlof and Kranton $(2000)^{7}$, student $i$ chooses the optimal combination of subjects $y_{i}$ maximizing the following utility function:

\footnotetext{
${ }^{6}$ The non-pecuniary pay-off derives from being a member of a group net of the cost faced to fitting in the social category and adopting its prescribed characteristics/behaviours.

${ }^{7}$ See Section 2.1 .
} 


$$
U_{i}=U_{i}\left(w\left(y_{i}, \boldsymbol{\epsilon}_{\boldsymbol{i}}\right) y_{i}\left(k_{i}\right) ; I_{i}\left(y_{i} ; c_{i}, \boldsymbol{\epsilon}_{\boldsymbol{i}}\right), \mathbf{P}\right)
$$

Similarly to Humlum et al. (2012), the pecuniary pay-off $w\left(y_{i}, \boldsymbol{\epsilon}_{\boldsymbol{i}}\right) y_{i}\left(k_{i}\right)$ is defined as a function of the choice $y_{i}$, skills $k_{i}$ and individual characteristics $\boldsymbol{\epsilon}_{\boldsymbol{i}}$. The non-pecuniary pay-off $\left(I_{i}\left(y_{i} ; c_{i}, \boldsymbol{\epsilon}_{\boldsymbol{i}}\right), \mathbf{P}\right)$ is a function of student $i$ 's choice $\left(y_{i}\right)$, gender as a social category $c_{i}$, its prescribed behaviours $\mathbf{P}$, and $i$ 's characteristics $\boldsymbol{\epsilon}_{\boldsymbol{i}}{ }^{8}$

The maximization process is the result of simultaneous evaluations of the expected pecuniary pay-off and the utility deriving from self-identification. If student $i$ does not care about identity the optimal choice $y_{i}^{*}$ is specializing in male subjects which allows her to maximize the return of her human capital investments, similarly to what standard economic models of educational decisions usually suggest. ${ }^{9}$ If student $i$ cares only about identity the optimal choice $y_{i}^{*}$ is specializing in the most-likely-choice of the same-gender group.

These two scenarios describe the two corner solutions of the utility maximization problem. However, in the real world, interior solutions are more likely. What the student cares about is maximizing her own total utility. She will not maximize the pecuniary pay-off in isolation, ignoring the non-pecuniary pay-off or vice versa. She will choose $y_{i}$ to maximize her own utility function, which is a combination of the two.

It is worth to note, that boys conforming with their own reference groups are able to maximize both pay-offs at the same time. For instance, consider a boy and a girl and assume that they are rational agents aiming to maximize their utility. Suppose that Literature is a "girly" subject, i.e. studied mostly by female students, while Mathematics is a "male" subject, i.e. studied mostly by male students. In a potential scenario, they have identical skills and they are both relatively better in Mathematics than in Literature. In this case, for the boy there is no conflict with respect to what his gender identity prescribes and what he should choose according to the expected monetary return. The

\footnotetext{
${ }^{8}$ As suggested by Humlum et al. (2012) this is a simplified version of the general framework reported in Section 2.1. where the utility of individual $i$ was assumed to depend on other people's actions as well.

${ }^{9}$ In fact, according to empirical evidence stereotyped male subjects, i.e. studied mostly by male students, have a higher pecuniary return.
} 
decision is more difficult for the girl. If she decides to study Mathematics, she bears the cost deriving from the mismatch of her choice with the gender prescribed one. She would decide to study Literature (maximizing her present non-pecuniary utility) if the utility of conforming to the gender stereotype exceeds the cost of renouncing to a higher expected monetary pay-off.

\section{Empirical Framework}

\subsection{A Model of Educational Choices and Gender Identity}

In the present analysis, differences in preferences across gender explain the part of gender bias in educational choices that cannot be explained by differences in abilities. ${ }^{10}$ In fact, the non-pecuniary component of students' utility function explains why high-ability female students might ultimately choose subjects leading to low-paying careers. If the pecuniary pay-off was the only component of a student's utility function, after controlling for abilities, this choice would be considered irrational and ultimately detrimental.

The main challenge in empirical applications of choice models is that only choices and grades, used as proxies of skills, are observable, while both preferences and expectations about the choice-specific outcomes are unknown. In this paper, I assume that boys and girls have similar expectations about the monetary returns of educational choices. For instance, they are aware that studying Engineering has a higher monetary return than studying Literature. ${ }^{11}$ Thus, I test two hypotheses: first, subject-specific abilities cannot explain by themselves differences in educational choices across gender; second, unobserved individual preferences are gender stereotyped. If the first hypothesis is verified, it means that differences in preferences and expectations play a role in educational choices. If the second hypothesis is verified, unobserved individual preferences are heterogeneous by gender, as boys and girls have the same expectations by assumption.

\footnotetext{
${ }^{10}$ Abilities and skills are considered as synonyms and used interchangeably

${ }^{11}$ Experimental evidence suggests it is a plausible assumption. Comparing subjective expectation data with objective measures, Zafar (2011a) and Zafar (2011c) find that the subjective data match up well with objective measures. For example, in the case of expected salary in the various majors, students seem to be aware of income differences across majors.
} 
The intuition is that two (observably) identical students, a boy and a girl, achieving the same grades at school, should choose the same subjects. If only the pecuniary pay-off matters, their "optimal" choice is the educational path associated with the highest expected monetary return given their abilities constraint. Any deviation from the "optimal" choice, reflects differences in preferences. The objective is to test if those individual preferences follow a gendered pattern, i.e. if students conform to the most-likely-choice of their gender group.

It is worth pointing out the distinction between "gender" and "gender identity". Being a girl does not necessarily mean behaving "girly". "Gender" ("sex") is an exogenously assigned characteristic. Conversely, gender stereotypes are the simplistic generalizations about the gender attributes, differences, and roles of individuals which define gender identity. Thus, characteristics such as the aversion to risk and competition and low selfefficacy might be considered attributes of the female gender identity as they are more likely to be manifested among girls than boys.

I consider the last stage of a three-period educational choice model for students in secondary education between 16 and 18 years old. In the first period, students are between the ages of 11 and 14 and they study the same subjects. At the end of this period, at age 14, they undertake National Curriculum assessments in the three core subjects of Mathematics, English and Sciences, which provide records of attainment in the subjects. In the second period, students are between the ages of 14 and 16 and they are able to choose from among a broad set of subjects. They decide which subjects to study taking into account their abilities, preferences and expectations, normally for a total of ten different courses. Thus, at the end of the second period, they get a grade for each subject studied and gain a better knowledge about both their preferences and abilities. This information guides the student in the selection of the subjects for the last two years of secondary education. I model this choice as a function of subjects-specific abilities measured at the end of the second period, controlling for previous attainments in the three core subjects.

The subject choice is defined as a continuous variable (henceforth called "masculinity score") which varies between 0 and 1 , with 1 corresponding to a male stereotyped choice, i.e. a choice which is more likely to be made by a boy, and 0 to a female stereotyped 
choice, i.e. a choice which is more likely to be made by a girl. I use the grades obtained in the second period to compute the average grade in male subjects and the average grade in female subjects, i.e. the average grade achieved in those subjects chosen more frequently by boys and by girls, respectively. A detailed description of the choice and grades variables is given in Section 5.1.

As noted previously, I want to investigate whether boys and girls make different choices, all (observable) conditions being equal. I estimate a model for the masculinity score $y_{i}$ at age 16 using Ordinary Least Squares (OLS), separately for boys and girls who are denoted respectively by the superscript B and G:

$$
\begin{gathered}
y_{i s}^{B}=\alpha_{0}^{B} b_{i s}+\alpha_{1}^{B} b_{i s} * \text { mgrade }_{i s}+\alpha_{2}^{B} b_{i s} * \text { fgrade }_{i s}+ \\
\beta_{0}^{B}\left(1-b_{i s}\right)+\beta_{1}^{B}\left(1-b_{i s}\right) * \text { mgrade }_{i s}+\beta_{2}^{B}\left(1-b_{i s}\right) * \text { fgrade }_{i s}+ \\
\Theta^{B} \mathbf{X}_{i s}+\Phi_{s}^{B} F_{s}+\epsilon_{i s}^{B} \\
y_{i s}^{G}=\alpha_{0}^{G} b_{i s}+\alpha_{1}^{G} b_{i s} * \text { mgrade }_{i s}+\alpha_{2}^{G} b_{i s} * \text { fgrade }_{i s}+ \\
\beta_{0}^{G}\left(1-b_{i s}\right)+\beta_{1}^{G}\left(1-b_{i s}\right) * \text { mgrade }_{i s}+\beta_{2}^{G}\left(1-b_{i s}\right) * \text { fgrade }_{i s}+ \\
\Theta^{G} \mathbf{X}_{i s}+\Phi_{s}^{G} F_{s}+\epsilon_{i s}^{G}
\end{gathered}
$$

where mgrade $_{i s}$ and fgrade $_{i s}$ are respectively the average grade in male subjects and the average grade in female subjects obtained at the end of the second period for student $i$ attending the school $s, b_{i s}$ is a dummy equal to 1 if mgrade $_{i s}$ is higher than fgrade $_{i s}$ and equal to 0 otherwise.

The coefficients $\alpha_{1}^{B}\left(\alpha_{1}^{G}\right)$ and $\alpha_{2}^{B}\left(\alpha_{2}^{G}\right)$ represent the change of the masculinity score given a marginal change in the grade in male and female subjects respectively, for those boys (or girls) who are relatively better in male than female subjects, $b_{i s}=1$. The coefficients $\beta_{1}^{B}\left(\beta_{1}^{G}\right)$ and $\beta_{2}^{B}\left(\beta_{2}^{G}\right)$ are the corresponding coefficients but for boys (or girls) who are relatively better in female than male subjects, $b_{i s}=0$. The parameter $\alpha_{0}^{B}$ 
$\left(\alpha_{0}^{G}\right)$ is the intercept of the masculinity score equation when $b_{i s}=1$ while $\beta_{0}^{B}\left(\beta_{0}^{G}\right)$ is the corresponding intercept when $b_{i s}=0$.

The vector $\mathbf{X}_{i s}$ contains a number of control variables that are likely to affect subject choice including child characteristics, family socio-economic background, neighborhood and school characteristics, and the average attainments achieved in the three core subjects in the first period as a proxy of general cognitive skills. ${ }^{12} F_{s}$ is a dummy variable which takes value 1 if the child studies in the school $s$ and 0 otherwise. It controls for schoolspecific unobserved heterogeneity. $\epsilon_{i s}^{B}$ and $\epsilon_{i s}^{G}$ are two normally distributed error terms.

As defined in equation 4 and 5 by the dummy $b$, students can be divided in two types: those who are relatively better in male subjects $\left(\theta_{M}\right)$ and those who are relatively better in female subjects $\left(\theta_{F}\right)$. I expect to find that subject-specific-skills are important in determining the subject choice and that in general students follow their talents. In this case, an increase in the grade in male subjects increases their choice of male subjects (see Panel A of Table 1). This is valid both for girls $\left(\alpha_{1}^{G}>0\right.$ for the type $\theta_{M}$ and $\beta_{1}^{G}>0$ for the type $\left.\theta_{F}\right)$ and boys $\left(\alpha_{1}^{B}>0\right.$ for the type $\theta_{M}$ and $\beta_{1}^{B}>0$ for the type $\left.\theta_{F}\right)$. Similarly, an increase in the grade in female subjects increases girls' choice of female subjects $\left(\alpha_{2}^{G}<0\right.$ for the type $\theta_{M}$ and $\beta_{2}^{G}<0$ for the type $\left.\theta_{F}\right)$ and the same for boys $\left(\alpha_{2}^{B}<0\right.$ for the type $\theta_{M}$ and $\beta_{2}^{B}<0$ for the type $\left.\theta_{F}\right) .{ }^{13}$

Remarkably, if a female student values the pecuniary more than the non-pecuniary payoff, the marginal change of the masculinity score would be higher (in absolute values) in case of an increase in the grade in male subjects than for an equal increase in the grade in female subjects. This is because she knows that male subjects are more likely to have a higher monetary return than female subjects. For boys, there is no trade-off between the pecuniary and the non-pecuniary pay-offs because they can maximize both by choosing male subjects.

Furthermore, I expect to find that students' choice is marginally shaped by notions of

\footnotetext{
${ }^{12}$ The complete list of control variables is reported in Table A1 in Appendix A. All variables included in the vector $\mathbf{X}_{i s}$ are either time constant or are measured at the same time as the dependent variable. The only exception is the mean attainments achieved in the first period.

${ }^{13}$ Note that an increase in the masculinity score corresponds to the choice of more courses in male subjects while a decrease indicates more female subjects. See Section 5.1 for the definition of the masculinity score indicator.
} 
gender congruence. The non-pecuniary component adds a utility premium to the students' utility function. This is key in explaining why boys are relatively more responsive than girls to an increase in the grade in male subjects while girls are more responsive than boys to an increase in the grade in female subjects, other things being equal (see Panel B of Table 1).

Finally, I expect that students have a natural inclination to choose the subjects in which they have a "comparative advantage", i.e. in which they perform relatively better. For example, a girl of the type $\theta_{M}$ would more likely than a girl of type $\theta_{F}$ to sacrifice part of her identity for a higher pecuniary pay-off. ${ }^{14}$ In this case an increase in the grade in male subjects would increase the masculinity score relatively more for a girl of the type $\theta_{M}$ than for a girl of the type $\theta_{F}\left(\alpha_{1}^{G}>\beta_{1}^{G}\right)$ and the opposite in case of a an increase in the grade in female subjects $\left(\left|\alpha_{2}^{G}\right|<\left|\beta_{2}^{G}\right|\right)$ (see Panel C of Table 1 ).

\subsection{Self-Selection in Single-Sex Schools}

A strategy to isolate the contribution of gender-identity to gender educational segregation is comparing students in single and mixed-sex schools. The hypothesis to test is that students in single-sex schools are less likely to follow gender stereotyped patterns in educational choice than their counterparts enrolled in mixed-schools. In the absence of the other gender, students are freer to follow their talents departing from their gender role without incurring in any social sanction. If this is the case I would expect to find that girls and boys in single-sex schools are likely to maximize their pecuniary pay-off and that an increase of their grades has the same effect on subject choice for boys and girls.

However, students in mixed and in single-sex schools might not be comparable and concern regarding the internal validity of this approach might arise. Presumably, students do not randomly self-select into single-sex schools. For instance, single-sex schools might draw a particular selection of students with stronger motivations and higher expectations or might select their students offering specific curricula, having a specific religious orientation

\footnotetext{
${ }^{14}$ Indeed, for the first girl, the opportunity cost of self-identification is higher than for the second one. As discussed in Section 6.2, the opportunity cost of conforming to the gender stereotypes might vary according to the level of students' abilities.
} 
or being more selective in student admission. The unobservable heterogeneity might affect both school choice and the subject choice. For example, a career-oriented female student might be more likely to choose a single-sex school and select a typically male curriculum. In such a case, comparing differences in educational choices between students in single-sex and mixed schools via a simple difference in the estimated coefficient of the masculinity score model, can overstate the true impact of being in a single-sex school on subject choice. This would make it difficult to recover the "true" effects of attainments on subject choice.

Roy (1951) offers an early discussion of self-selectivity. The econometric discussion has been followed by Gronau (1974), Lewis (1974) and Heckman (1974). Since then, selfselection has been widely discussed. ${ }^{15}$ I use the endogenous switching regression model which allows correcting for the selection bias (Quandt, 1972). In this model the observed outcome (equation 6) derives from two truncated distributions (equation 7 and equation 8):

$$
\begin{aligned}
y_{i} & =z y_{i}^{1}+(1-z) y_{i}^{0} \\
y_{i}^{0} & =\alpha_{0}+\boldsymbol{\beta}_{\mathbf{0} \boldsymbol{v}} \mathbf{V}_{i 0}+\epsilon_{i 0} \quad \text { if } z_{i}=0 \\
y_{i}^{1} & =\alpha_{1}+\boldsymbol{\beta}_{\mathbf{1} \boldsymbol{v}} \mathbf{V}_{i 1}+\epsilon_{i 1} \quad \text { if } z_{i}=1
\end{aligned}
$$

where $y_{i}$ is the masculinity score observed for the student $i$, which is equal to $y_{i}^{0}$ for those students choosing to study in a mixed school $\left(z_{i}=0\right)$ and $y_{i}^{1}$ for those students choosing to study in a single-sex school $\left(z_{i}=1\right) ; \mathbf{V}_{0 i}$ and $\mathbf{V}_{1 i}$ are two vectors of observable characteristics at individual, school and neighbourhood level. Notably, this model allows both the intercepts term $\left(\alpha_{0}, \alpha_{1}\right)$ and the vector of parameters $\left(\boldsymbol{\beta}_{\mathbf{0} \boldsymbol{v}}\right.$ and $\left.\boldsymbol{\beta}_{\mathbf{1} \boldsymbol{v}}\right)$ to differ between those students in mixed and single-sex schools, respectively. Finally, $\epsilon_{i 0}$ and $\epsilon_{i 1}$ represent an error term for those students enrolled respectively in mixed and single-sex schools. The probability of enrolling in one or the other school, is the outcome of an unobservable latent variable $z_{i}^{*}$ following a linear model:

\footnotetext{
${ }^{15} \mathrm{~A}$ complete review of the econometric methods used to solve sample selection and self-selection issue is beyond the scope of this paper. Mokhtarian and Cao (2008) provide a recent survey of common methods to address self-selection.
} 


$$
\mathrm{z}_{i}^{*}=\gamma \mathbf{W}_{i}+u_{i}
$$

$z_{i}^{*}$ is linked to an observed dichotomous indicator $z_{i}$ which takes value 1 if $z_{i}^{*}>0$, i.e. if the student is enrolled in a single-sex school, and 0 if $z_{i}^{*} \leq 0$, i.e. if the student is in a mixedsex school. $\mathbf{W}_{i}$ is a vector of variables affecting the decision to enroll either in a single-sex or mixed school and $\gamma$ is the vector of the associated parameters. $\epsilon_{i}$ and $u_{i}$ are assumed to be correlated but independent of $\left(\mathbf{V}_{0}, \mathbf{V}_{1}\right)$ and $\mathbf{W}_{i}$ and $E\left[\epsilon_{i 0} \mid \mathbf{V}_{0}, z_{i}, \mathbf{W}_{i}\right]=E\left[\epsilon_{i 0} \mid \mathbf{V}_{0}, z_{i}\right]$ and $E\left[\epsilon_{i 1} \mid \mathbf{V}_{1}, z_{i}, \mathbf{W}_{i}\right]=E\left[\epsilon_{i 1} \mid \mathbf{V}_{1}, z_{i}\right]$.

However, the correlation between the error term $u_{i}$ and the main equations error terms $\epsilon_{i 0}$ and $\epsilon_{i 1}$, implies that the latent variable $z_{i}^{*}$ is not independent of $\epsilon_{i}$ and that the ordinary least square estimation of model (7) and (8) would be inconsistent. The error terms $\left(u_{i}, \epsilon_{i 0}, \epsilon_{i 1}\right)$ are assumed to have a trivariate normal distribution with zero mean and covariance matrix:

$$
\Omega=\left(\begin{array}{ccc}
\sigma_{u}^{2} & \cdot & \cdot \\
\sigma_{u 0} & \sigma_{0}^{2} & \cdot \\
\sigma_{u 1} & \sigma_{10} & \sigma_{1}^{2}
\end{array}\right)
$$

where $\sigma_{u}^{2}=1$ is the variance of the error term in the selection equation (9), and $\sigma_{0}^{2}$ and $\sigma_{1}^{2}$ are the variance of the error terms in the two main equations (7) and (8). Finally, $\sigma_{u 0}$ is the covariance of $u_{i}$ and $\epsilon_{i 0}, \sigma_{u 1}$, is the covariance of $u_{i}$ and $\epsilon_{i 1}$. Note that, " $\sigma_{10}$ is the covariance of the errors $\epsilon_{i 0}$ and $\epsilon_{i 1}$ of the two main equations and it is not identified as $y_{i}^{0}$ and $y_{i}^{1}$ are never observed simultaneously" (Maddala, 1983).

I jointly estimate the main equation and the selection equation allowing for correction between error terms (Lokshin and Sajaia, 2004). ${ }^{16}$ A key advantage of the endogenous switching regression model is that it allows for heterogeneity in the effect of covariates

\footnotetext{
${ }^{16}$ The model can also be estimated following a two-step procedure. However, I use the full information maximum likelihood (FIML) method, which is recognized to be more efficient although computationally intensive. The results obtained are very similar to those obtained running a selection model à la Heckman twice, changing the dependent variable of the selection equation for each of the two regimes considered. However, the switching model is a more efficient approach given that the Heckman type procedure considers two different selection equations, one for each regime rather than one single selection model.
} 
across single-sex and mixed schools' regime. In fact, after accounting for endogenous self-selection, the question remains whether enrolling in a single-sex school has an average impact on subject choice over the entire sample of students through a shift in the intercept in the masculinity score function, or it also has an additional slope effect.

Essentially this model allows a full set of interaction terms between regime status and the control variables included in the model. The identity model described above predicts that studying in a single-sex school affects how grades in female and male subjects matter in defining students' choices. In extreme cases, the absence of the opposite-sex pressure cancels out the non-pecuniary component from the students' utility function. In these cases students would maximize their pecuniary pay-off and they would be completely responsive to any change in grades and there are no significant differences in choice across gender after controlling for abilities.

Even though the endogenous switching model does not strictly require an exclusion restriction, practical experience suggests that it performs poorly if it is not included. Convincing identification of this model requires that at least one variable in $W_{i}$ is excluded from the main equations (7) and (8) (Woodridge, 2002). I use the density of single-sex schools in each Local Education Authority (LEA) ${ }^{17}$ as an instrument which affects the probability to attend a single-sex school but not directly the subject choice. The implicit assumption is that students reside in the same $L E A$ as their schools. Unfortunately, it is not possible to verify this directly because information about students' residence is not available. ${ }^{18}$ However, the definition of $L E A$ seems to be wide enough to offer to those students willing to study in a single-sex school the option to choose a single-sex school in the same $L E A$ where they live. In each $L E A$ around eight percent of Key Stage 5 schools are single-sex schools and in some $L E A s$ this percentage rises to 25 percent.

\footnotetext{
${ }^{17} \mathrm{~A} L E A$ is a local authority that has the responsibility for education within its jurisdiction in England. Currently there are 152 local education authorities in England.

${ }^{18}$ According with the UK Department of Education, during the 2007/2008 academic year around 13.8 percent of sixth-form students did not reside in the $L E A$ where they attended the school.(see http://www.education.gov.uk/rsgateway/DB/SFR/s000786/index.shtml)
} 


\section{$5 \quad$ Data and Sample Description}

The dataset used in the empirical analysis is the $N P D$, an administrative annual register of all pupils in primary and secondary state maintained schools in England. This analysis focuses on students enrolled in the compulsory and post-compulsory secondary education tracks. Key Stage 2 marks the end of primary education and the beginning of secondary education. Compulsory secondary education is divided into two Key Stages: Key Stage 3 for students aged 11-14 years, and Key Stage 4 for those aged 14-16 years. After that, students may decide either to leave education or follow post-compulsory secondary education until the age of 18 .

As for Key Stage 2, at the end of Key Stage 3 students take the Key Stage 3 National Curriculum tests in English, Mathematics and Sciences. Similarly, pupils enter the General Certificate of Secondary Education (GCSE) at the end of Key Stage 4 and the General Certificate of Education (GCE) at the end of Key Stage $5 .{ }^{19}$ Both qualifications consist of a range of exams in single subjects which students have chosen from a range of different options. The grades which a candidate has achieved in each subject attempted are listed on the certificates.

The longitudinal design of this survey allows matching students' prior attainments at Key stage 2 and 3, with later attainments at Key Stage 4 and 5. Key Stage 2 National Curriculum tests and Key Stage 4 exams are prepared at national level and marked externally. Therefore, they are more reliable than Key Stages 1 and 3 tests and, after controlling for unobservable characteristics at school level, students' performances are fully comparable across schools. ${ }^{20}$

In this paper, I restrict the sample to the cohort of Key Stage 5 final candidates for the $2007 / 2008$ academic year. As noted, the NPD is a census for the whole population of

\footnotetext{
${ }^{19}$ The GCSE are not compulsory, but are by far the most common qualification at the end of Key Stage 4. Possible alternative are equivalent vocational or occupational exams. During Key Stage 5, students may take a number of courses leading to approved qualifications, including General Certificate of Education Advanced-level (GCE A-level) qualifications, GCE Advanced Subsidiary qualifications (GCE applied AS level) and A-levels in applied subjects (GCE applied A-level). See Sections A2 in Appendix A for more detailed information on the English educational system and qualification.

${ }^{20}$ Note that following a series of issues regarding the marking, Key Stage 3 National Curriculum assessments were abolished in 2008.
} 
pupils in state schools. Thus, our sample contains the full population of students of the cohort considered, which totals about 412,000 observations. The students considered are those continuing their studies after compulsory education into Key Stage 5. Further, I exclude those students enrolling into a vocational track and I only consider those choosing an academic track, i.e. those who at the end of compulsory schooling choose to study for GCE qualifications or equivalent. Arguably, the decision to continue into further education (or to choose academic instead of vocational qualifications) may depend upon characteristics which are not randomly distributed across the population. Unfortunately, I am not able to control for censoring bias because of data limitations. Thus, the results of this analysis are not representative of those students dropping out after compulsory education or enrolled into a vocational track. Nevertheless, my sample remains representative of about 65 percent of the whole population of students at this school age. ${ }^{21}$

Although the $N P D$ is primarily an administrative register, it provides a number of variables that help in identifying the main child characteristics and the household socioeconomic background. The NPD includes a variable for ethnic origin and the main language spoken at home. Moreover, it includes a variable indicating student eligibility to receive Free School Meals (FSM). This is an assisted meal program which subsidies low-income households with nutritionally balanced, low-cost or free lunches for children at school. Finally, the NPD includes the Income Deprivation Affecting Children Index $(I D A C I)$, which is an indicator of income deprivation amongst children, capturing the proportion of children experiencing income deprivation in their area of residence. ${ }^{22}$ The variable "Gifted and talented student" identifies those children who have been recognized by their schools as having an ability to develop significantly ahead of their year group.

In Table 2, I report the characteristics of the sample of girls and boys used in the estimations. Girls represent around 53 percent of the full sample. In the third column I report the average difference between girls and boys and a t-test for differences in mean between the two samples. Given the large sample dimension, extremely small and non-notable differences have been found to be statistically significant. ${ }^{23}$.

\footnotetext{
${ }^{21}$ For further details, see "Participation in Education, Training and Employment by 16-18 Year Olds in England", Department for Education, http://www.education.gov.uk/rsgateway/DB/SFR/s000938/index.shtml.

${ }^{22}$ For further details, see Table A1 in Appendix A.

${ }^{23}$ Nevertheless, the empirical analysis in the following section is performed separately for girls and boys
} 
It is worth noting that the IDACI score is about 16 percent, which is close to the median value and lower than the mean value of the IDACI score in England. Additionally, around 8 percent of students received a FSM at least once during Key Stage 5, which is slightly below the national average of FSM beneficiaries in secondary school which is around 10 percent. This suggests that the sample used in this study represents a more affluent sub-population in comparison to the national average. ${ }^{24}$ About 18 percent of the sample comprises students from ethnic minorities and more specifically around 4 percent are Bangladeshi/Pakistani and Indian, 1 percent are Chinese and Black Caribbean, 3 percent are Black African and 6 percent are from other undefined ethnic groups (not included in the analysis). It is important to note that students from ethnic minorities are more likely to enroll in single-sex schools. The high incidence of students from ethnic minorities in single-sex schools may indicate that many single-sex schools are religious schools or might signal the presence of segregation phenomenon at school or $L E A$ level.

In addition to the NPD data, I use data from the "LEA and School Information Service" which allows the matching of $L E A$ and school comparative information for all public (primary and secondary) schools in England. It contains at-school-level information on the ethnic composition, the percentage of students receiving FSM, or recognized with Special Educational Needs $(S E N)^{25}$ and the percentage of students speaking English as a first language.

\subsection{Defining Educational Choices and Attainments}

As anticipated in previous sections, I define a variable named masculinity score, which describes the student's subject choice. More precisely, the masculinity score is a continuous variable measuring how much the subject choice of each student reflects the average choice of a typical male student. A high masculinity score corresponds to a choice made predominantly by male students; a low masculinity score indicates that the selected subjects are more likely to be chosen by female students. In order to define the masculinity score,

\footnotetext{
${ }^{24} \mathrm{It}$ is, however, not surprising given that it includes only those students continuing in post-compulsory education.

${ }^{25}$ For further details, see Table A1 in Appendix A.
} 
I aggregate all courses offered at Key Stage 5 into 10 subject groups (Mathematics, English, Sciences, Health, Economics, Humanities, Languages, Arts, Design and Technology, Information and Communications Technology).

Keeping in mind that at Key Stage 5 students are able to select their own curriculum, assume that student $i$ chooses to study three subjects: Mathematics $(s=1)$, English $(s=2)$ and Sciences $(s=3)$. More specifically, student $i$ chooses $N_{1 i}$ courses in the Mathematics group; $N_{2 i}$ courses in the English group and $N_{3 i}$ courses in the Sciences group. Student $i$ 's choice can be described by a set of 3 count variables and the masculinity score $\left(\right.$ Masc $\left._{i}\right)$ computed as the average of three partial masculinity scores as follow:

$$
\begin{gathered}
\operatorname{Masc}_{i}=\frac{1}{3}\left(\frac{\sum_{j=1}^{J} 1\left(N_{1 j}=N_{1 i}\right) b o y_{j}}{\sum_{j=1}^{J} 1\left(N_{1 j}=N_{1 i}\right)}\right)+\left(\frac{\sum_{j=1}^{J} 1\left(N_{2 j}=N_{2 i}\right) b o y_{j}}{\sum_{j=1}^{J} 1\left(N_{2 j}=N_{2 i}\right)}\right)+ \\
\left(\frac{\sum_{j=1}^{J} 1\left(N_{3 j}=N_{3 i}\right) b o y_{j}}{\sum_{j=1}^{J} 1\left(N_{3 j}=N_{3 i}\right)}\right)
\end{gathered}
$$

where $j=1, \ldots, J$ indexes students in the $L E A ; b o y_{j}$ is equal to 1 if student $j$ is male and 0 if female, and $1($.$) is the indicator function, equal to 1$ if the condition in the small brackets is true and 0 otherwise. The numerator of the first addend in large brackets is the number of boys in the $L E A$ taking the same number of courses of Mathematics as the student $i$, and the denominator is the total number of students in the $L E A$ (boys and girls) making the same choice.

Suppose that in the same $L E A$ where the student $i$ studies, 80 percent of students choosing $N_{1}$ courses of Mathematics are boys, 40 percent of students choosing $N_{2}$ courses of English are boys and 20 percent of students choosing $N_{3}$ courses of Sciences are boys. ${ }^{26}$ The masculinity score of student $i$ is therefore $(0.8+0.4+0.2) / 3=0.47 .{ }^{27}$ The masculinity score of the student $i$ can be defined by generalizing the equation above as follow:

\footnotetext{
${ }^{26}$ It is worthwhile to note that, given that most of those choosing $N_{1}$ Mathematics courses are boys, this choice can be considered as a stereotyped male choice, while the opposite is true for the choice of $N_{3}$ mostly chosen by female students.

${ }^{27}$ Note that given that the masculinity score depends not only on individual choices but also on schoolmates' choices, two students choosing the same curricula not necessarily end up having the same masculinity score if they are studying in different LEAs.
} 


$$
\operatorname{Masc}_{i}=\frac{1}{n\left(S_{i}\right)} \sum_{s \in S_{i}}\left(\frac{\sum_{j=1}^{J} 1\left(N_{s j}=N_{s i}\right) b o y_{j}}{\sum_{j=1}^{J} 1\left(N_{s j}=N_{s i}\right)}\right)
$$

where $s=1, n\left(S_{i}\right)$ is the subject area, $S_{i}$ the set of subject areas in which courses are taken by student $i$, and $n\left(S_{i}\right)$ the number of these subject areas. $N_{s k}$ is the number of courses taken in subject area $s$ by student $k(k=i, j)$.

The masculinity score takes values between 0 and 1 , where 1 correspond to a curriculum chosen exclusively by boys and 0 to a curriculum chosen exclusively by girls. I standardize the masculinity score computing the z-score transformation (henceforth called masculinity z-score), where the numerator is the difference between the masculinity score of the curriculum chosen by student $i$, and the average masculinity score of all students enrolled in the same LEA. The denominator is the standard deviation of the masculinity score within the same $L E A$ :

$$
\operatorname{Masc}_{i z}=\frac{\operatorname{Masc}_{i}-\operatorname{mean}\left(\operatorname{Masc}_{L E A}\right)}{s d\left(\operatorname{Masc}_{L E A}\right)}
$$

A high masculinity z-score indicates a typically male choice. Thus, it indicates a "conformist" choice if the student is a boy or an "anti-conformist" choice if the student is a girl.

The next step is defining how to measure students' performance. In Key Stage 2 a student's grade is the average score obtained in each subject studied and takes values between 0 and 100. In Key stage 4 student grades are reported on an eight-point scale: $\mathrm{A}^{*}, \mathrm{~A}, \mathrm{~B}, \mathrm{C}, \mathrm{D}, \mathrm{E}, \mathrm{F}$ and $\mathrm{U}$, with $\mathrm{U}$ indicating a fail. I derive a continuous variable converting the alphabetical code to a numeric code from 0 to 7 , where 0 corresponds to $\mathrm{U}$ and $\mathrm{A}^{*}$ to 7 . Using all grades received for the courses studied at Key Stage 4, I define two variables for Key Stage 4 attainments: the "grade in male subjects" and the "grade in female subjects". ${ }^{28}$ The first is the average grade obtained at the end of

\footnotetext{
${ }^{28}$ At Key Stage 4 most students choose at least one typically male and one typically female coursesper-subject pair and thus the grades in male and grade in female subjects are available for both of them. However, the 7 percent and 11 percent of the students I do not observe the grade in male subjects and the grade in female subjects. I call them respectively "just-male-grades subgroup" and "just-female-grades subgroup". For these two subgroups I impute the missing grades. The following analysis includes imputed
} 
Key Stage 4 in the $N_{s i}$ courses chosen mainly by boys within the same $L E A$. Conversely, the "grade in female subjects" is the average grade obtained at Key Stage 4 in the $N_{s i}$ courses-per-subject chosen mainly by girls. ${ }^{29}$

In the previous example, the average grade obtained in $N_{1}$ Mathematics courses would be used to compute the grade in male subjects given that 80 percent of those students making the same choice are males. Conversely the average grade obtained in $N_{2}$ English courses and in $N_{3}$ Science courses would be used to compute the grade in female subjects given that the same choice is predominantly made by female students.

\section{$6 \quad$ Results}

The following section reports some descriptive statistics about test scores and subject choice (Section 6.1), the results of the estimation of the masculinity z-score for girls and boys (Section 6.2) and for students in mixed and single-sex schools (Section 6.3). In the last part of this section, the timing of the gender stereotypes' activation is studied comparing choices at Key Stage 5 with the choices at Key Stage 4 (Section 6.4).

\subsection{Descriptive Statistics: What Do Students Choose and How Do They Perform}

Gender identity cannot be observed directly. In an attempt to isolate the effect of gender stereotypes on educational choices, I compare attainments (Table 3) and subject choice (Table 4) for boys and girls, and for students in single-sex and mixed schools (Table 6 and 7 , respectively).

Table 3 reports the average grade achieved in Mathematics, English and Science during

data. Excluding imputed observations does not change the results.

${ }^{29}$ The sample is composed of 47 percent of boys and 53 percent of girls. Thus, the grade obtained for each subject studied is considered in the computation of the average grade in male subjects whether more than 47 percent of male students of the same $L E A$ chose it. Conversely, it is included in the computation of the average grade in female subjects. 
Key Stage 2, and in female and male subjects during Key Stage 4 and 5, separately by gender. During Key Stage 2 the only subjects where girls are better than boys is English. Conversely, during Key Stage 4 and 5 girls are consistently better, both in male and female subjects. ${ }^{30}$

It is worthwhile noting that during Key Stage 4 girls' grade in female subjects is slightly higher than their grade in male subjects and the opposite for boys. ${ }^{31}$ Because of their comparative advantage (girls in female subjects and boys in male subjects), at Key Stage 5 girls should specialize in female subjects and boys in male subjects if their choice is based exclusively on their abilities. As reported in Table 4, boys' masculinity z-score at Key Stage 5 is indeed higher than girls' at the $1 \%$ significance level. In other words, boys choose relatively more male subjects than girls (or girls choose more female subjects than boys).

However, gendered patterns in subject choice emerges even comparing two students, a girl and a boy, who got the same grades in both female and male subjects. Specifically, I consider pairs of "identical" boys and girls and I distinguish between three groups of students: the "Worst Students", the "Medium Students" and the "Best Students". The Worst students achieve the lowest grade in both male and female subjects and the best students the highest. ${ }^{32}$ The mean masculinity z-score is computed for each pair (Table 5). Girls and boys with equal attainments make different choices and this happens across all the "identical"-students' sub-samples considered. ${ }^{33}$ This suggests that the students based their choice on elements others than their abilities. Notably, both girls and boys follow their gender stereotypes: girls choose more female subjects and less male subjects than boys.

As noted above, I compare students in single-sex and mixed schools to test whether gender identification affects educational choices. The same statistics presented in Table 3 and Table 4 are shown separately for the two school types respectively in Panel A and B of

\footnotetext{
${ }^{30}$ All differences in grades across gender are significantly different from zero at the $1 \%$ significance level.

${ }^{31}$ For both boys and girls the difference between the mean grade in female and male subjects is significantly different from zero at the $1 \%$ significance level.

${ }^{32}$ To define the worst, the average and the best students groups, I divide the grade in female subjects and the grade in male subjects in tertiles.

${ }^{33}$ The masculinity score for boys and girls across all the "identical"-students' sub-samples is significantly different from zero at the $1 \%$ significance level.
} 
Table 6 .

As found previously, girls are always better than boys and relatively better in female than in male subjects, which may explain why the girls' masculinity z-score is always lower in both single and mixed schools. However, girls studying in a single-sex school choose a more male-oriented curriculum: their masculinity score z-score is higher than in mixed schools. ${ }^{34}$ This might be the case for two reasons: first, single-sex schools drive a non-random selection of students based on curriculum; second, a single-sex environment discourages gender stereotypes.

Supporting the first hypothesis, there is evidence that on average, both boys and girls in single-sex schools are more specialized in male subjects than students in mixed schools. Single-sex schools might offer a more male oriented curriculum than mixed schools. However, the potential non-random self-selection into single-sex schools based on curriculum choice does not explain why girls studying in single-sex schools make choices, on average, more similar to "identical" male students, as shown in Table 7.

\subsection{Does Gender Identity Matter? Comparing Female and Male Students' Choices at Key Stage 5}

In Table 8 I report the results of the estimation of the equation (4) for girls and (5) for boys distinguishing those students who are relatively better in female subjects (first and second columns) and those better in male subjects (third and fourth columns). ${ }^{35}$ The masculinity z-score is estimated using OLS with fixed effects at school level. ${ }^{36}$ Using fixed unobservable effects at school level eliminates any fixed factor that impacts the

\footnotetext{
${ }^{34}$ In both cases the t-test rejects the null hypothesis at the $1 \%$ significance level.

${ }^{35}$ To test the robustness of the masculinity $z$-score and the grades definition, I estimate the subject choice model using instead of the masculinity z-score the choice of at least two courses in Mathematics and statistics (which can be considered a typical male choice given that among those students doing this choice more than 60 percent are boys). Similarly, I compute the average grade obtained in those Mathematics courses (corresponding to the grade in male subjects in the main model) and the average grades obtained in art/humanities courses for those who are choosing two or more coursers within Humanities studies, logic, philosophy, law and sociology (corresponding to the grade in female subjects in the main mode given that among those students doing this choice around 65 percent are girls). The results reported in Table A6 confirm the estimates found using the masculinity score model and reported in Table 8.

${ }^{36}$ Standard errors are corrected for clustering at the school level.
} 
educational choices of all students within the same school. ${ }^{37}$ I test the null hypothesis that the coefficients estimated through OLS are equal to the fixed effects estimate and I reject the null hypothesis at 1 percent significance level, which confirms that school unobservable characteristics lead to a bias. ${ }^{38}$

The overall results suggest that students respond to an increase of grades choosing more subjects in the area they have more ability, as described in Panel A of Table 1. The estimated coefficient for the grade in male subjects is positive (an increase of the grade in male subjects leads to the choice of more male subjects) while it is negative for the grade in female subjects (an increase of the grade in female subjects leads to the choice of more female subjects, i.e. a decrease of the masculinity z-score).

Notably, students associate a higher importance to traditionally male subjects which are expected to have better returns in the future. In fact, the magnitude of the marginal effect of an increase in the grade in male subjects is bigger than the marginal effect of an increase in the grade in female subjects. ${ }^{39}$ This might suggest that students perceive education as an investment and choose those subjects associated with a higher expected monetary return.

As expected (and reported in Panel B of Table 1), girls' demand of male subjects is less responsive than boys' to an increase of the grade in male subjects. ${ }^{40}$ On average, an increase of one unit of the grade in male subjects has an effect on masculinity z-score bigger for boys than for girls (0.134 and 0.165 standard deviation for boys and 0.081 and 0.124 for girls, within the group of students who are relatively better in female and male subjects, respectively). ${ }^{41}$ The results are consistent with a model in which gender identity

\footnotetext{
${ }^{37}$ For the sake of clarity I only show the coefficient and standard error for the main variables. Full results are available on request.

${ }^{38}$ OLS estimated coefficients (not reported) are qualitatively similar to the ones estimated using fixed effects at school level.

${ }^{39}$ The estimated coefficients of the grade in male subjects and the grade in female subjects are significantly different at the $1 \%$ significance level (p-value $=0.000$ ) for all students regardless of their gender and their comparative advantage in either male or female subjects.

${ }^{40}$ As noted above, following gender stereotypes has different implications in terms of monetary pay-off maximization for boys and girls. Indeed, if girls follow their stereotype they might face a cost in term of expected monetary pay-off given that typical female educational path are often associated with low paid occupations. Conversely, if boys conform to the male stereotype they maximize both the non-pecuniary and the pecuniary pay-off.

${ }^{41}$ For both type of students, the estimated coefficients of the grade in male subjects for boys and girls are significantly different from one another at the $1 \%$ significance level ( $\mathrm{p}$-value $=0.000$ ).
} 
adds a positive non-pecuniary pay-off to the girls' utility whether they decide to specialize in the same-gender stereotyped subjects.

However, this is valid just for girls. In fact, male students accept choosing stereotypically female subjects if they are good at them. Within those students who are relatively better in female subjects, the increase of one unit of the grade in female subjects decreases the masculinity z-score equally for girls (0.044 standard deviation) and for boys (0.065 standard deviation). The same is true within those students who are relatively better in male subjects (an additional unit of the grade in female subjects decreases the masculinity $z$-score by 0.025 standard deviation for girls and 0.039 standard deviation for boys). ${ }^{42}$

Interestingly, boys and girls are willing to accept the cost of acting against their stereotypes and choose (on the margin) more of the opposite-gender stereotyped subjects, when they have a comparative advantage in them (as shown in Panel $\mathrm{C}$ of Table 1). In fact, the marginal increase of the masculinity z-score due to an increase of the grade in male subjects is relatively higher for those girls who are better in male subjects than those better in female subjects (respectively 0.124 and 0.081 standard deviation). ${ }^{43}$ Similarly, the coefficient of the grade in female subjects is, in absolute value, higher for boys who are relatively better in female than in male subjects (respectively -0.065 standard deviation and -0.039$).{ }^{44}$

The opportunity cost of conforming to the gender stereotypes might vary according to the level of student's abilities. To allow for non-linearity in the grades profile, the two continuous variables for grades are split into tertiles (High, Medium and Low grades) ${ }^{45}$ and then combined to create nine possible categories of students according to their grades, as reported in Table $9 .^{46}$

\footnotetext{
${ }^{42} \mathrm{~A}$ t-test of difference between the two regression coefficients of the grade in female subjects for boys and girls gives a $\mathrm{p}$-value $=0.831$ and a $\mathrm{p}$-value $=0.342$ respectively among those students relatively better in male and female subjects.

${ }^{43}$ The two estimates are different from one another at the $1 \%$ significance level (p-value:0.000).

${ }^{44}$ The difference between the estimated coefficients for the two types of male students is statistically different from zero at the $5 \%$ significance level (p-value:0.049).

${ }^{45}$ The plot of the residuals of the subject choice equation against the two grades suggests the existence of a nonlinear pattern. I use a likelihood ratio test to compare the likelihood of a model containing continuous variable to the likelihood of a model with the variable coded as categorical. For all models estimated I found a significant difference in likelihood which indicates that the linear model would lead to inconsistent estimations.

${ }^{46}$ Full results are available on request.
} 
In order to facilitate the interpretation of the results, I group these nine categories into three sub-groups of students: the "Best Students" group including those who have high grades either in female subjects or in male subjects or in both; the "Medium-Low Students" group including those who have medium or low grades in male and/or female subjects and the "Polarized Students" group including those with high grade in one subject area and low grade in the other. ${ }^{47}$ These three groups represent respectively the 61 percent, 36 percent and 3 percent of the estimation sample.

The direction of the relation between masculinity z-score and grades remains the same once linearity is relaxed, which means that a linear representation is still a pretty accurate approximation of the overall relationship. As reported in Table 9, (i) on average grades matter more for the best than for the worst students; (ii) the grade effect gap between girls and boys is minimum within the best students group; and (iii) evidence of gender stereotyped choices show up particularly for girls with low grades or in the Polarized group.

For the Best students, the opportunity cost of renouncing gender identity is lower than for the others. They are more inclined than the other students to accept a gender identity loss and adjust their choice selecting more of the opposite-gender stereotyped subjects. For this reason, girls and boys at the top of grade distribution behave similarly. For example, within the group of students with the highest grades in both male and female subjects $(\mathrm{HfHm})$, an increase of one unit of the grade in male subjects leads to a higher increase of the masculinity z-score for girls than for boys (0.273 and 0.222 standard deviation for girls and boys, respectively). Similarly, an increase of one unit of the grade in female subjects decreases the masculinity z-score of 0.060 standard deviation for girls and 0.100 standard deviation for boys. ${ }^{48}$

Conversely, within the Medium-Low group, the estimated coefficients of the grade in

\footnotetext{
${ }^{47}$ The "Best Students" group includes those students with: HfHm=High grade in female subjects (fgrade) and High grade in male subjects (mgrade); MfHm=Medium fgrade and High mgrade; HfMm=High fgrade and Medium mgrade. The "Medium-Low Students" group include those students with MfMm=Medium fgrade and medium mgrade; MfLm=Medium fgrade and Low mgrade; LfMm=Low fgrade and Medium mgrade. The "Polarized Students" group includes those students with LfHm=Low fgrade and High mgrade; HfLm=High fgrade and Low mgrade and LfLm=Low fgrade and Low mgrade.

${ }^{48} \mathrm{In}$ both cases, the estimated coefficients are different from one another at the $1 \%$ significance level (p-value:0.000).
} 
female subjects are in most cases higher for girls than for boys ${ }^{49}$ and the opposite for the grade in male subjects ${ }^{50}$, which is consistent with a model in which acting according to the own gender stereotype adds a positive pay-off to student's utility.

The strongest evidence of gendered preferences appears among those girls in the polarized group and in particular among the LfHm subgroup. Despite their low grade in female subjects and their high grade in male subjects, the grade in female subjects is the only one affecting their subject choice. An increase of the grade in female subjects leads them to choose more female subjects regardless of their comparative advantage in male subjects (one unit in their grade in female subjects decreases the masculinity z-score by 0.131 standard deviation).

\subsection{Does the School Environment Matter? Comparing Stu- dents' Choices in Single-Sex and Mixed Schools at Key Stage 5}

There is a large debate in the literature about the pros and cons of single-sex versus mixed schools. One of the arguments in favour of single-sex schools is that they are more likely to encourage students to pursue academic paths according to their talents rather than their gender stereotypes. Comparing the subject choice of boys and girls in mixed and single-sex schools helps in identifying if and to what extent abilities and gender roles matter in educational choices.

In Panel A of Table 10, I report the results of the masculinity z-score estimation using OLS with school fixed effects separately for boys and girls in mixed and single-sex schools. ${ }^{51}$ As discussed above, OLS estimates might be biased due to a self-selection problem. In Panel $\mathrm{B}$ and $\mathrm{C}$ the masculinity z-score equation for boys and for girls is estimated using an endogenous switching regression model to correct for non-random selection into single-

\footnotetext{
${ }^{49}$ The estimated coefficient of the grade in female subjects for boys and girls are different from one another within the group $M f m m$ (p-value=0.098), MfLm (p-value=0.027) and are not statistically different for the students in the $L f M m$ group (p-value $=0.126$ ).

${ }^{50} \mathrm{~A}$ t-test of difference between the two regression coefficients of the grade in male subjects for boys and girls gives a p-value $=0.024$ for the group $M f L m$ and a p-value $=0.096$ and p-value $=0.126$ respectively for the $M f M m$ and $L f M m$ groups.

${ }^{51}$ Full results are available on request.
} 
sex schools. I report both the results from the selection equation and the two main equations corresponding to the masculinity z-score for those students in mixed and singlesex schools. As in the equations (4) and (5), I distinguish between the effect of an increase in grades for those students relatively better in female subjects and those better in male subjects. $^{52}$

As reported in the selection equation results, studying in a $L E A$ with high density of single-sex schools significantly increases the probability of enrolling in a single-sex school. At the bottom of Panel B and C of Table 10 I report the correlation coefficients $\rho_{0}=\sigma_{u 0} / \sigma_{0}$ and $\rho_{1}=\sigma_{u 1} / \sigma_{1}$, which represent the correlation between the error terms of the selection equation and the subject choice equation for students in mixed and single-sex schools, respectively. Both the sign and significance of these coefficients give an interesting insight into the selection issue. $\rho_{1}$ is positive and significant for all models estimated, which suggests that students in a single-sex school share unobserved characteristics leading them to specialize more in a male curriculum than a random student in the sample.

After controlling for self-selection, the results of the fixed effect estimation (Panel A, Table 10) are substantially confirmed. According to my findings, both grades in male and female subjects matter to girls' choice in mixed schools. An increase of the grade in male subjects leads them to choose more male subjects (the masculinity z-score increases by 0.075 and 0.140 standard deviation respectively for those better in female and those better in male subjects), and an increase of the grade in female subjects makes them choose more female subjects (the masculinity z-score decreases by 0.041 and 0.045 standard deviation respectively for those better in female and those better in male subjects).

Conversely, in single-sex schools any change in grades leads girls to choose more male subjects, regardless of which subject area they have a comparative advantage in. In single-sex schools, girls are able to maximize their pecuniary pay-off without paying the cost of acting against their gender stereotypes as in mixed schools. In fact, in single-sex schools the cost of not conforming is null because of the absence of the opposite-sex. For example, among those better in female subjects, an increase of their grade in female subjects does not affect their choice whereas each additional unit of the grade in male

\footnotetext{
${ }^{52}$ Full results are available on request.
} 
subjects leads to an increase of the masculinity z-score of 0.148 standard deviation (Panel B, Table 10). ${ }^{53}$

I find similar results for boys. In single-sex schools the grade in male subjects is the only one which matters to their subject choice whereas in mixed schools both grades affect the masculinity $z$-score. An additional unit of the grade in male subjects increase the masculinity z-score by 0.152 standard deviation in single-sex schools and 0.127 in mixed schools among boys relatively better in female subjects and 0.123 versus 0.147 among boys relatively better in male subjects.

Nevertheless, as noted above, boys do not have to choose between maximizing either the expected monetary pay-off or the non-pecuniary pay-off (given that male subjects have higher expected monetary return than female subjects). This suggests that even if choosing male stereotyped subjects does not imply an identity cost, boys are more inclined to the choice of male stereotyped subjects.

Beyond affecting subject choice through reducing the identity pressure, as in the case of girls, or strengthening gender stereotypes, as for boys, studying in single-sex schools might increase the choice of male subjects through other mechanisms. The preference of male subjects in single-sex schools might reflect a change in risk taking behaviour and more specifically a lower risk aversion. Those students who exhibit a relatively high degree of risk aversion tend to discount the future relatively more than students that are less risk averse. For example, if girls' prefer immediate pay-offs to delayed pay-offs they would choose more female than male subjects. Indeed, the first one generating an immediate non-pecuniary utility, while the second one is expected to have a higher monetary return at later stages. The single-sex environment might not only reduce the cost of not conforming behaviours but also reduce risk aversion and make them more patient about the future as previous experimental works on girls' risk preferences in single-sex schools showed (Booth and Nolen, 2011 and 2012).

As noted, the effect of the single-sex environment on educational choices is controversial in

\footnotetext{
${ }^{53}$ Similarly, among female students better in male subjects a marginal increase of both the grade in female subjects and the grade in female subjects lead them to choose more male subjects (the masculinity $z$-score increases respectively by 0.064 and 0.095 standard deviation)(Panel C, Table 10).
} 
the literature because of student selection of school type. In order to check the robustness of my results, I repeat the same exercise excluding all students enrolled in single-sex schools and redefining within the mixed schools group a sub-sample of pseudo-single-sex schools, i.e. those schools where the percentage of same-gender students is higher than 70 percent. The pseudo-single-sex schools represent about 5 percent of the mixed schools sample.

The results (reported in Table A7) substantially confirmed previous results. Being in schools with a high percentage of same-gender students attenuates the gender identity for girls, pushing them to choose more male subjects and reinforces the choice of stereotypically male subjects for boys. This exercise excludes any potential endogenous self-selection bias and confirms that the estimates reported in Table 10 (Panel B and C) identify a causal effect and not a simple correlation.

\subsection{When Do Gender Stereotypes Develop? Comparing Male and Female Students' Choices at Key Stages 4 and 5}

I investigate when gender identity starts affecting educational choices, looking at earlier subject choices. I compute the masculinity z-score at Key Stage 4 as for Key Stage 5 masculinity z-score. Students choose Key Stage 4 subjects in the last year of Key Stage 3 when they are around 14 years old.

Similarly to the Key Stage 5 choices model, the masculinity z-score at Key Stage 4 is modeled as being determined by previous attainments and a vector of lagged variables. Given that Key Stage 3 tests are not national assessments, I use Key Stage 2 tests which are comparable across schools. Thus, after controlling for school (fixed) unobserved characteristics, the reliability of the comparisons is assured. However, given that before Key Stage 4 all students study the same subjects (English, Mathematics and Science) it is not possible to construct the two variables of grades, i.e. the grade in male subjects and grade in female subjects, as defined in Section 5.1. For this reason, I control instead for the average grade in Mathematics and in English. 
I test the null hypothesis that the coefficients estimated through OLS are not different from the consistent fixed effects model estimates and I reject the null hypothesis at the 1 percent level. The results reported in Table 11 are including school fixed effects. ${ }^{54}$

According to my findings, the patterns observed at Key Stage 5 choice are already present at Key Stage 4. For example, among those students who are relatively better in Mathematics, the estimated coefficients of both grades are, in absolute value, higher for boys than for girls (respectively 0.007 for boys versus 0.005 for girls for the grade in Mathematics and -0.006 for boys versus -0.005 for girls for the grade in English). This finding suggests that talents matter relatively more for boys than for girls in the choice of Key Stage 4 subjects. ${ }^{55}$

Furthermore, assuming that English is a traditionally female subject and Mathematics a traditionally male subject, boys are not reluctant to enroll in more female subjects if they are good at them. Among those students who are relatively better in English, the grade in English is the only one affecting boys' subject choice. Among those students who are relatively better in Mathematics, a marginal increase of the grade in English decreases the masculinity z-score(i.e. increasing the choice of courses of English) relatively more for boys (0.006 standard deviation) than for girls (0.005 standard deviation) ${ }^{56}$

Conversely, gender stereotypes seem to affect girls' choices. Any additional unit of the grade in Mathematics, among those students who are relatively better in this subject, pushes boys more than girls to increase their masculinity z-score respectively by 0.007 versus 0.005 standard deviation. ${ }^{57}$

Therefore if gender stereotypes affect educational choice already at Key Stage 4, the stereotyped choice observed at Key Stage 5 might be the result of previous investments in terms of effort and training in specific subjects. As Staw (1976) argues, individuals keep investing to justify to themselves the initial investment and it may result in the

\footnotetext{
${ }^{54}$ Full results are available on request.

${ }^{55}$ The regression coefficients of both grades for boys and for girls are statistically different from zero at the $1 \%$ significance level ( $\mathrm{p}$-value $=0.000)$.

${ }^{56}$ The regression coefficients of both grades for boys and for girls are statistically different from zero at the $1 \%$ significance level $(\mathrm{p}$-value $=0.001)$.

${ }^{57} \mathrm{As}$ reported above, the regression coefficient of the grade in Mathematics for boys and for girls is statistically different from zero at the $1 \%$ significance level ( $\mathrm{p}$-value $=0.000$ ).
} 
persistence of unproductive tasks. That is why Staw highlights the importance of beliefs and gender stereotypes assimilated during childhood.

In Table 12, I report the estimates for Key Stage 5 masculinity z-score model as a function of Key Stage 2 grades. ${ }^{58}$ The objective of this analysis is to investigate whether Key Stage 5 choices depend on early abilities measured at Key Stage 2, regardless of previous investments and choices. Given that during Key stage 1 and Key stage 2 there are no elective subjects, the marginal effect of a change in Key stage 2 grades on Key stage 5 choice indicates how much abilities matter unconditionally to previous choices and how much beliefs and stereotypes acquired during childhood affect later choices.

According to my results, among those students who are relatively better in Mathematics at Key Stage 2, a marginal increase of the grade in Mathematics is associated with a higher increment of the Key Stage 5 masculinity z-choice for boys than for girls (respectively 0.031 and 0.028 standard deviations). ${ }^{59}$ Conversely, boys and girls react similarly to an increase in the grade in female subjetcs which confirms that boys are less reluctant than girls to choose opposite-sex-stereotyped subjects, as found above. This is confirmed also for male students who are relatively better in English. Indeed, an increase of their grade in Mathematics decreases their masculinity z-score by 0.006 standard deviations making them choose relatively more of those subjects on which they have a comparative advantage. Thus, the propensity to make gender-conforming choices is already present at Key Stage 2 and it is reaffirmed (or even reinforced) by later choices and investments.

\section{Conclusions and Discussion}

This paper provides a framework to understand why talented girls choose educational careers leading to low-paid jobs. I investigate the existence of a non-pecuniary pay-off associated with gender identity which constrains girls' educational choices and more generally might justify the different educational trajectories of girls and boys. The hypothesis

\footnotetext{
${ }^{58}$ Full results are available on request.

${ }^{59}$ The two coefficients are significantly different from one another at $1 \%$ significance level (pvalue $=0.000$ ).
} 
is that gender stereotypes might contribute to the under-representation of women in more technical/quantitative majors which are more likely to lead to better paid and more prestigious position in the labour market.

According to my results, the belief that men are naturally more skilled at technical/quantitative domains is empirically unfounded and attainments are not able to explain alone subject choices. Indeed, boys and girls performing equally in the same subjects, choose differently and according to their own gender stereotype. Boys tend to choose more traditionally male subjects and girls more traditionally female subjects.

Despite a decline overtime in gender differences in subject choice in England (Wikeley and Stables, 1999; Francis, 2000), I find that gender stereotypes affect girls' educational choices at Key Stage 4, when students have to choose for the first time. In general, boys follow their talents more than girls even if this means making an anti-conformist choice. Gender stereotypes matter relatively more for girls who on the margin might give up higher pecuniary returns to follow a stereotyped path.

I find that there is no monotonic relation between subject choice and attainments. An additional unit of grade in male subjects increases the male specialization of the best female students more than the others. This finding is consistent with the hypothesis that the better a girl is at traditionally male subjects the higher is her incentive to specialize in male subjects. The opportunity cost of choosing differently from the majority of the other female students, is relatively higher for those girls at the bottom of the grade distribution than for the best female students. In other words girls and boys at the top of grade distribution behave similarly.

Furthermore, I find evidence that attending a sixth form single-sex school alleviates the influence of gender stereotypes for girls. In the absence of gender pressure, gender stereotypes lessen and choices are based mainly on the maximization of their expected monetary pay-off. Similarly, single-sex environment reinforces the choice of stereotypically male subjects for boys. This finding suggests that single-sex contexts foster less stereotypical behaviours for girls and the opposite for boys.

This research represents a step further in the comprehension on the impact of identity on 
educational choice. It provides interesting insights in the debate on the origin of gender segregation in education. In order to attenuate the gendered educational segregation, effective policies should be addressed to eliminate what divert students from following their talents. If at the origin of gender segregation there is, as shown, a problem of choices instead of low performance, policies improving either girls schooling or attainments do not yield effective results. Further, as I found that gender issues affects diversely students achieving different levels of performance, policies should target different groups of students separately. Finally, according to my results the school environment plays a crucial role in shaping girls' and boys' educational preferences. The findings about the favorable environment offered by single-sex schools suggest that the creation of a gender-friendly environment at school can reduce educational sex segregation.

This analysis shows the existence of gender stereotyped preferences and choices in education and reassure the importance of the school environment. Further research is needed to study the mechanisms generating gender identity and gender-specific preferences in education, such as the development of different expectations, motivation and risk preferences. 


\section{Tables}

Table 1 Estimating the Masculinity Score: How to Interpret the Coefficients of grade in male and in female subjects

PANEL A

\begin{tabular}{|c|c|c|c|c|}
\hline & \multicolumn{2}{|c|}{ Girls } & \multicolumn{2}{|c|}{ Boys } \\
\hline & $\theta_{M}$ & $\theta_{F}$ & $\theta_{M}$ & $\theta_{F}$ \\
\hline$\Delta m g r a d e$ & $\alpha_{1}^{G}>0$ & $\beta_{1}^{G}>0$ & $\alpha_{1}^{B}>0$ & $\beta_{1}^{B}>0$ \\
\hline$\Delta$ fgrade & $\alpha_{2}^{G}<0$ & $\beta_{2}^{G}<0$ & $\alpha_{2}^{B}<0$ & $\beta_{2}^{B}<0$ \\
\hline \multicolumn{3}{|c|}{ PANEL B } & \multicolumn{2}{|l|}{ PANEL C } \\
\hline & \multicolumn{2}{|c|}{ Girls vs. Boys } & \multicolumn{2}{|c|}{$\theta_{M}$ vs. $\theta_{F}$} \\
\hline & $\theta_{M}$ & $\theta_{F}$ & Girls & Boys \\
\hline$\Delta m g r a d e$ & $\alpha_{1}^{G}<\alpha_{1}^{B}$ & $\beta_{1}^{G}<\beta_{1}^{B}$ & $\alpha_{1}^{G}>\beta_{1}^{G}$ & $\alpha_{1}^{B}>\beta_{1}^{B}$ \\
\hline$\Delta$ fgrade & $\left|\alpha_{2}^{G}\right|>\left|\alpha_{1}^{B}\right|$ & $\left|\beta_{2}^{G}\right|>\left|\beta_{1}^{B}\right|$ & $\left|\alpha_{2}^{G}\right|<\left|\beta_{2}^{G}\right|$ & $\left|\alpha_{2}^{B}\right|<\left|\beta_{2}^{B}\right|$ \\
\hline
\end{tabular}

Note: See equations (4) and (5). The coefficients reported in the table describe the marginal changes of the grade in male (mgrade) and in female subjects (fgrade) for students relatively better in male subjects $\left(\theta_{M}\right)$ and in female subjects $\left(\theta_{F}\right)$. Panel A: students follow exclusively their talents. Panel B: non-pecuniary component adds a utility premium to the students' utility function (comparing boys and girls). Panel C: students choose relatively more of those subjects in which they have a "comparative advantage" (comparing the two types of students $\theta_{M}$ and $\theta_{F}$ ). In both Panel $\mathrm{A}$ and $\mathrm{B}$ the coefficients of mgrade are always $>0$ and the coefficients of the fgrade are always $<0$. 
Table 2 Sample Description: Comparing Girls and Boys

\begin{tabular}{lcc|cc|ccc}
\hline & \multicolumn{2}{c|}{ Girls } & \multicolumn{2}{c|}{ Boys } & \multicolumn{2}{c}{ Girl-Boy } & \\
& N(216,883) & \multicolumn{2}{c}{ N(195,021) } & \multicolumn{2}{c}{ Difference } & t test \\
& Mean & Std.Dev & Mean & Std.Dev & Mean & S.E. & p-value \\
\hline Child characteristics (Key & & & & & & & \\
Stage 5) & & & & & & & \\
$\quad$ Age & 16.70 & $(0.001)$ & 16.75 & $(0.001)$ & -0.047 & $(0.002)$ & $(0.00)$ \\
$\quad$ White & 0.82 & $(0.001)$ & 0.83 & $(0.001)$ & -0.008 & $(0.001)$ & $(0.00)$ \\
Bangladeshi/Pakistani & 0.04 & $(0.000)$ & 0.04 & $(0.000)$ & 0.001 & $(0.001)$ & $(0.06)$ \\
Chinese & 0.01 & $(0.000)$ & 0.01 & $(0.000)$ & -0.001 & $(0.000)$ & $(0.03)$ \\
Indian & 0.04 & $(0.000)$ & 0.04 & $(0.000)$ & -0.003 & $(0.001)$ & $(0.00)$ \\
Black Caribbean & 0.02 & $(0.000)$ & 0.01 & $(0.000)$ & 0.005 & $(0.000)$ & $(0.00)$ \\
Black African & 0.03 & $(0.000)$ & 0.02 & $(0.000)$ & 0.004 & $(0.001)$ & $(0.00)$ \\
Others & 0.06 & $(0.001)$ & 0.06 & $(0.001)$ & 0.002 & $(0.001)$ & $(0.01)$ \\
First language: English & 0.88 & $(0.001)$ & 0.88 & $(0.001)$ & -0.004 & $(0.001)$ & $(0.00)$ \\
Gifted \& Talented student & 0.22 & $(0.001)$ & 0.21 & $(0.001)$ & 0.008 & $(0.001)$ & $(0.00)$ \\
SEN & 0.04 & $(0.000)$ & 0.07 & $(0.001)$ & -0.028 & $(0.001)$ & $(0.00)$ \\
Socioeconomic Status (Key & & & & & & & \\
$\quad$ FSM & 0.08 & $(0.001)$ & 0.07 & $(0.001)$ & 0.009 & $(0.001)$ & $(0.00)$ \\
IDACI & 0.17 & $(0.000)$ & 0.16 & $(0.000)$ & 0.010 & $(0.001)$ & $(0.00)$ \\
Single-sex school & & & & & & & \\
$\quad$ Enrolled in Key Stage 3 & 0.15 & $(0.001)$ & 0.12 & $(0.001)$ & 0.036 & $(0.001)$ & $(0.00)$ \\
Enrolled in Key Stage 4 & 0.20 & $(0.001)$ & 0.15 & $(0.001)$ & 0.052 & $(0.001)$ & $(0.00)$ \\
Enrolled in Key Stage 5 & 0.15 & $(0.001)$ & 0.13 & $(0.001)$ & 0.025 & $(0.001)$ & $(0.00)$ \\
\hline
\end{tabular}

Note: Average values; standard deviation in parentheses. SEN= Special Educational Needs; IDACI= Income Deprivation Affecting Children Index; FSM=Free School Meals Eligibility. Ttest for differences in mean ( $\mathrm{p}$-value reported in the last column). 
Table 3 Attainments at Key Stage 3, 4 and 5

\begin{tabular}{lll|ll|ccc}
\hline & \multicolumn{2}{c|}{ Girls } & \multicolumn{2}{c|}{ Boys } & \multicolumn{2}{c}{ Girl-Boy } \\
& & & & \multicolumn{2}{c}{ Difference } & t test \\
& Mean & Std.Dev & Mean Std.Dev & Mean & S.E. & p-value \\
\hline $\begin{array}{l}\text { Grades at Key } \\
\text { Stage 2 }\end{array}$ & & & & & & & \\
$\quad$ Math & 72.15 & $(0.037)$ & 75.82 & $(0.040)$ & -3.66 & $(0.055)$ & $(0.000)$ \\
$\quad$ English & 70.03 & $(0.025)$ & 67.16 & $(0.027)$ & 2.87 & $(0.037)$ & $(0.000)$ \\
$\quad$ Science & 63.84 & $(0.021)$ & 65.00 & $(0.022)$ & -1.16 & $(0.031)$ & $(0.000)$ \\
Grades a Key & & & & & & & \\
Stage 4 & & & & & & & \\
$\quad \begin{array}{l}\text { Female } \\
\text { subjects }\end{array}$ & 4.95 & $(0.002)$ & 4.68 & $(0.003)$ & 0.27 & $(0.004)$ & $(0.000)$ \\
$\quad$ Male subjects & 4.91 & $(0.003)$ & 4.74 & $(0.003)$ & 0.17 & $(0.004)$ & $(0.000)$ \\
Grades at Key & & & & & & & \\
Stage 5 & & & & & & & \\
$\quad$ Female & & & & & & & \\
$\quad$ subjects & 3.20 & $(0.003)$ & 3.02 & $(0.004)$ & 0.18 & $(0.004)$ & $(0.000)$ \\
$\quad$ Male subjects & 3.23 & $(0.004)$ & 3.04 & $(0.004)$ & 0.19 & $(0.005)$ & $(0.000)$ \\
\hline
\end{tabular}

Note: Average values; standard deviation in parentheses. T-test for differences in mean ( $\mathrm{p}$-value reported in the last column).

Table 4 Masculinity Score at Key Stage 4 and 5

\begin{tabular}{|c|c|c|c|c|c|c|c|}
\hline & \multicolumn{2}{|c|}{ Girls } & \multicolumn{2}{|c|}{ Boys } & \multicolumn{2}{|c|}{$\begin{array}{c}\text { Girl-Boy } \\
\text { Difference }\end{array}$} & \multirow{2}{*}{$\begin{array}{l}\text { t test } \\
\text { p-value }\end{array}$} \\
\hline & Mean & Std.Dev & Mean & Std.Dev & Mean & S.E. & \\
\hline \multicolumn{8}{|c|}{$\begin{array}{l}\text { Masculinity score } \\
\text { Key Stage } 4\end{array}$} \\
\hline Score & 0.46 & $(0.000)$ & 0.47 & $(0.000)$ & -0.01 & $(0.000)$ & $(0.000)$ \\
\hline Z-score & -0.34 & $(0.002)$ & 0.30 & $(0.002)$ & -0.65 & $(0.003)$ & $(0.000)$ \\
\hline \multicolumn{8}{|c|}{ Key Stage 5} \\
\hline Score & 0.45 & $(0.000)$ & 0.47 & $(0.000)$ & -0.02 & $(0.000)$ & $(0.000)$ \\
\hline Z-score & -0.35 & $(0.002)$ & 0.37 & $(0.003)$ & -0.72 & $(0.003)$ & $(0.000)$ \\
\hline
\end{tabular}

Note: Average values; standard deviation in parentheses. T-test for differences in mean (p-value reported in the last column). See Section 5.1 for the definition of the masculinity score. 
Table 5 Masculinity z-Score by Gender: Comparing Identical Boys and Girls

\begin{tabular}{lcc|cc|ccc}
\hline & \multicolumn{6}{c}{ Masculinity z-score (Key Stage 5) } \\
\hline & \multicolumn{2}{c}{ Girls } & \multicolumn{2}{c|}{ Boys } & \multicolumn{2}{c}{$\begin{array}{c}\text { Girl-Boy } \\
\text { Difference }\end{array}$} & t-test \\
& Mean & Std.Dev & Mean & Std.Dev & Mean & S.E. & p-value \\
\hline \multicolumn{2}{l}{ Grades (Key Stage4) } & & & & & & \\
Worst Students & 0.440 & $(0.000)$ & 0.460 & $(0.000)$ & -0.02 & $(0.000)$ & $(0.000)$ \\
Average Students & 0.440 & $(0.000)$ & 0.470 & $(0.000)$ & -0.02 & $(0.000)$ & $(0.000)$ \\
Best Students & 0.460 & $(0.000)$ & 0.480 & $(0.000)$ & -0.02 & $(0.000)$ & $(0.000)$ \\
\hline
\end{tabular}

Note: Average values; standard deviation in parentheses. T-test for differences in mean (pvalue reported in the last column). See section 5.1 for the definition of the masculinity score. Using a sub-sample of students who got the same grades in both female and male subjects. Worst Students, Average Students and Best Students groups are defined on the base of their grades and corresponds to the bottom, medium and top grades tertiles. 
Table 6 Grades at Key Stage 4 (Panel A) and Masculinity Score at Key Stage 5

(Panel B) Comparing Students in Single-Sex and Mixed Schools

PANEL A

\section{Grades (Key Stage 4)}

Mixed schools

Single-sex schools

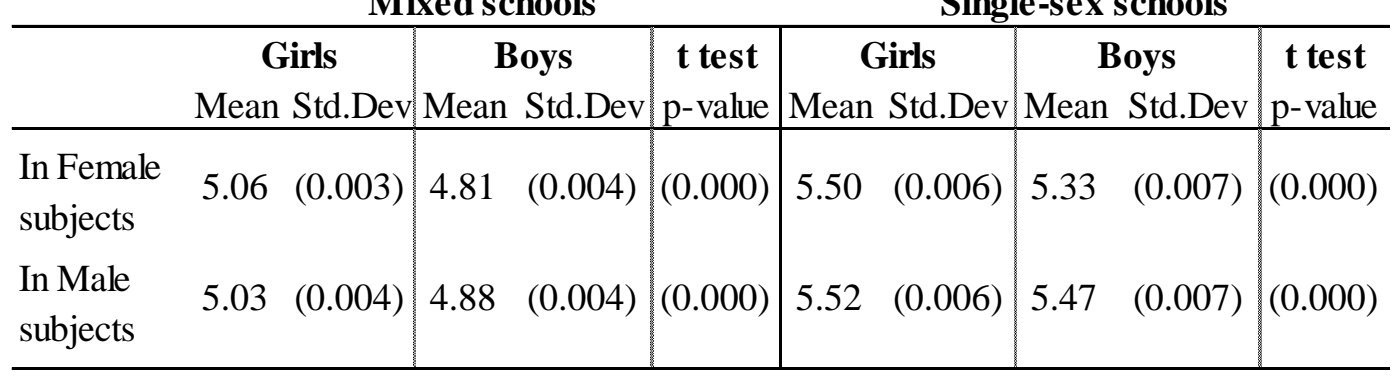

PANEL B

Masculinity score (Key Stage 5)

\begin{tabular}{lc|cc|c|cc|ccc|c}
\multicolumn{4}{c}{ Mixed schools } & \multicolumn{4}{c|}{ Single-sex schools } \\
\hline & \multicolumn{2}{c}{ Girls } & \multicolumn{2}{c|}{ Boys } & \multicolumn{1}{c|}{ t test } & \multicolumn{2}{c|}{ Girls } & \multicolumn{2}{c}{ Boys } & t test \\
& Mean Std.Dev & Mean & Std.Dev & p-value & Mean & S.E. & Mean & Std.Dev & p-value \\
\hline Score & 0.45 & $(0.000)$ & 0.47 & $(0.000)$ & $(0.000)$ & 0.46 & $(0.000)$ & 0.47 & $(0.000)$ & $(0.000)$ \\
Z-score & -0.35 & $(0.003)$ & 0.37 & $(0.003)$ & $(0.000)$ & -0.22 & $(0.005)$ & 0.40 & $(0.007)$ & $(0.000)$ \\
\hline
\end{tabular}

Note: Average values; standard deviation in parentheses. T-test for differences in mean across gender (p-value reported in the last column). See section 5.1 for the definition of the masculinity score. 
Table 7 Subject Choice at Key Stage 5: Comparing Female and Male Students Relatively Better in Male or Female Subjects

Key Stage 5 Masculinity z-score: OLS with Fixed Effect at School Level

\begin{tabular}{|c|c|c|c|c|}
\hline & \multicolumn{2}{|c|}{$\begin{array}{c}\text { Relatively better in female } \\
\text { subjects }\end{array}$} & \multicolumn{2}{|c|}{$\begin{array}{c}\text { Relatively better in male } \\
\text { subjects }\end{array}$} \\
\hline & Girls & Boys & Girls & Boys \\
\hline \multicolumn{5}{|l|}{ Grade (Key Stage 4) } \\
\hline In male subjects & $\begin{array}{c}0.081 * * * \\
(0.007)\end{array}$ & $\begin{array}{c}0.134 * * * \\
(0.010)\end{array}$ & $\begin{array}{c}0.124 * * * \\
(0.009)\end{array}$ & $\begin{array}{c}0.165^{* * *} \\
(0.011)\end{array}$ \\
\hline In female subjects & $\begin{array}{c}-0.044 * * * \\
(0.008) \\
\end{array}$ & $\begin{array}{c}-0.065^{* * * *} \\
(0.012)\end{array}$ & $\begin{array}{c}-0.025 * * * \\
(0.009)\end{array}$ & $\begin{array}{c}-0.039 * * * \\
(0.010)\end{array}$ \\
\hline Constant & $\begin{array}{c}-1.786 * * * \\
(0.114)\end{array}$ & $\begin{array}{c}-0.539 * * * \\
(0.130)\end{array}$ & $\begin{array}{c}-2.043 * * * \\
(0.114)\end{array}$ & $\begin{array}{c}-0.785 * * * \\
(0.129)\end{array}$ \\
\hline Adj. R-squared & 0.08 & 0.09 & 0.08 & 0.09 \\
\hline Observations & 139,364 & 119,449 & 139,364 & 119,449 \\
\hline
\end{tabular}

Note: Dependent variable: masculinity z-score measured at Key Stage 5 (see Section 5.1), estimated using OLS with fixed effects at school level. Standard error accounts school-level clustering (reported in parenthesis). Asterisks indicate significance at $* 0.1 * * 0.05 * * *$ 0.01 levels, respectively. The results reported in the first and third and in the second and fourth columns correspond to the estimation of the masculinity z-score respectively for girls (equation 4) and for boys (equation 5). Full results available on request. Control variables: mean grade at Key Stage 2, enrolled in a single-sex school at Key Stage 3, 4 and 5, child characteristics at Key Stage 5 (age, ethnicity, first language, Special Educational Needs (SEN), Gifted and Talented Cohort), Free School Meals (FSM)) and IDACI. 
Table 8 Subject Choice at Key Stage 5: Comparing the Best Students with the Worst Ones

Key Stage 5 Masculinity z-score: OLS with Fixed Effect at School Level

\begin{tabular}{|c|c|c|c|c|}
\hline \multirow{3}{*}{ Best students } & \multicolumn{2}{|c|}{ Girls } & \multicolumn{2}{|c|}{ Boys } \\
\hline & \multirow[t]{2}{*}{ Coef. } & \multirow[t]{2}{*}{ Std.Err. } & \multirow[t]{2}{*}{ Coef } & \multirow[t]{2}{*}{ Std.Err. } \\
\hline & & & & \\
\hline HfHm*mgrade & $0.273 * * *$ & $(0.015)$ & $0.222 * * *$ & $(0.019)$ \\
\hline HfHm*fgrade & $-0.060 * * *$ & $(0.014)$ & $-0.100 * * *$ & $(0.020)$ \\
\hline MfHm*mgrade & $0.083 * * *$ & $(0.023)$ & $0.051^{*}$ & $(0.030)$ \\
\hline MfHm*fgrade & -0.044 & $(0.035)$ & $0.072^{*}$ & $(0.043)$ \\
\hline HfMm*mgrade & $0.111 * * *$ & $(0.033)$ & $0.163 * * *$ & $(0.045)$ \\
\hline HfMm*fgrade & $-0.035^{*}$ & $(0.021)$ & $-0.149 * * *$ & $(0.036)$ \\
\hline \multicolumn{5}{|c|}{ Medium-Low students } \\
\hline MfMm*mgrade & $0.114 * * *$ & $(0.023)$ & $0.228 * * *$ & $(0.028)$ \\
\hline MfMm*fgrade & -0.029 & $(0.022)$ & -0.018 & $(0.031)$ \\
\hline LfMm*mgrade & $0.090 * * *$ & $(0.031)$ & $0.216^{* * *}$ & $(0.035)$ \\
\hline LfMm*fgrade & $-0.047 * *$ & $(0.020)$ & $-0.058 * * *$ & $(0.019)$ \\
\hline MfLm*mgrade & 0.000 & $(0.014)$ & $0.079 * * *$ & $(0.019)$ \\
\hline MfLm*fgrade & $-0.050 *$ & $(0.027)$ & -0.054 & $(0.038)$ \\
\hline LfLm*mgrade & $0.021 * *$ & $(0.009)$ & $0.084 * * *$ & $(0.009)$ \\
\hline LfLm*fgrade & $-0.118 * * *$ & $(0.011)$ & $-0.039 * * *$ & $(0.011)$ \\
\hline \multicolumn{5}{|c|}{ Polarized students } \\
\hline LfHm*mgrade & 0.036 & $(0.067)$ & -0.043 & $(0.070)$ \\
\hline LfHm*fgrade & $-0.131 * *$ & $(0.057)$ & -0.063 & $(0.058)$ \\
\hline HfLm*mgrade & -0.026 & $(0.037)$ & $0.101 * *$ & $(0.051)$ \\
\hline HfLm*fgrade & 0.008 & $(0.043)$ & -0.037 & $(0.068)$ \\
\hline Constant & $-1.211 * * *$ & $(0.121)$ & $-0.453 * * *$ & $(0.132)$ \\
\hline Adj. R-squared & \multicolumn{2}{|c|}{0.09} & \multicolumn{2}{|c|}{0.10} \\
\hline Observations & \multicolumn{2}{|c|}{139,364} & \multicolumn{2}{|c|}{119,449} \\
\hline
\end{tabular}

Note: Dependent variable: masculinity z-score measured at Key Stage 5 (see Section 5.1), estimated using OLS with fixed effects at school level. Standard error accounts school-level clustering. Asterisks indicate significance at $* 0.1 * * 0.05 * * * 0.01$ levels, respectively. Full resultsavailable on request. Mgrade=grade in male subjects; fgrade=grade in female subjects. Grade groups: $\mathrm{HfHm}=$ High grade in female subjects (fgrade) and High grade in male subjects (mgrade); MfMm=Medium fgrade and medium mgrade; LfLm=Low fgrade and Low mgrade; $\mathrm{MfHm}=$ Medium fgrade and High mgrade; LfMm=Low fgrade and Medium mgrade; LfHm=Low fgrade and High mgrade;HfMm=High fgrade and Medium mgrade; MfLm=Medium fgrade and Low mgrade; HfLm=High fgrade and Low mgrade. Control variables: mean grade at Key Stage 2, enrolled in a single-sex school at Key Stage 3,4 and 5, child characteristics at Key Stage 5 (age, ethnicity, first language, Special Educational Needs (SEN), Gifted and Talented Cohort), Free School Meals (FSM)), IDACI. 


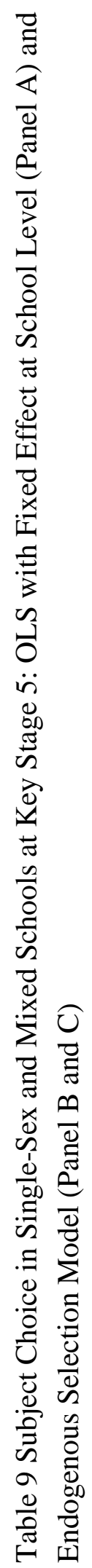

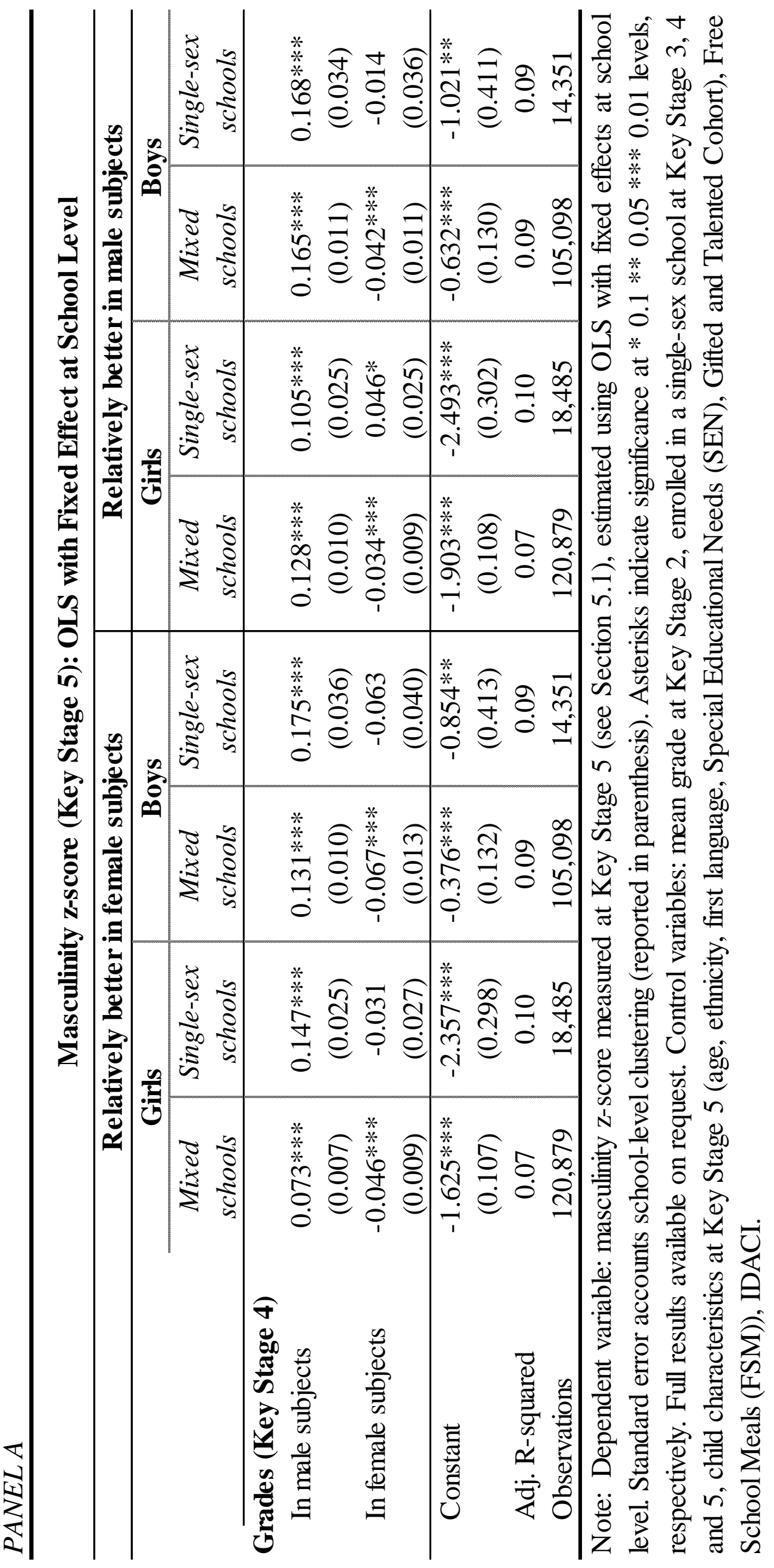




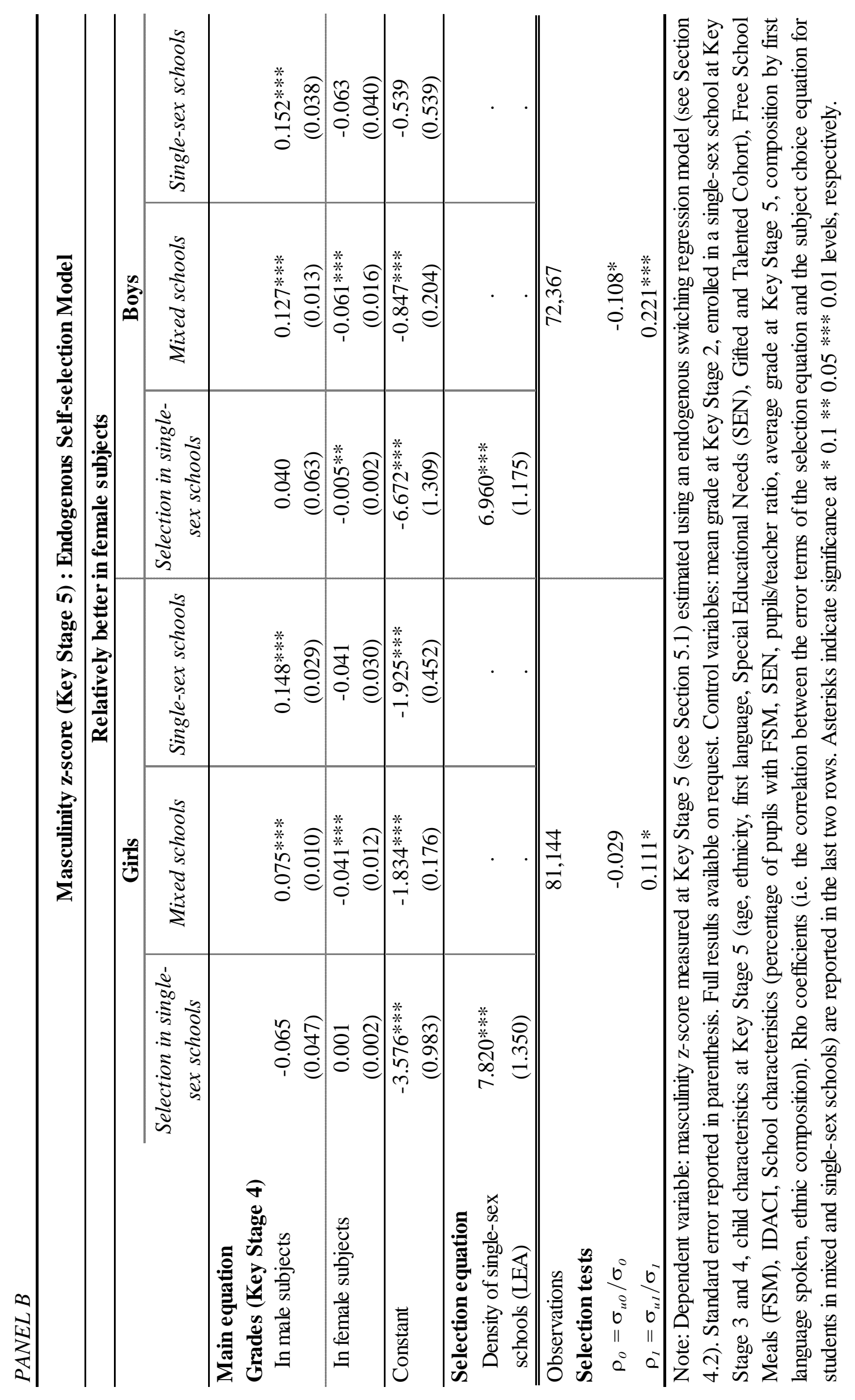




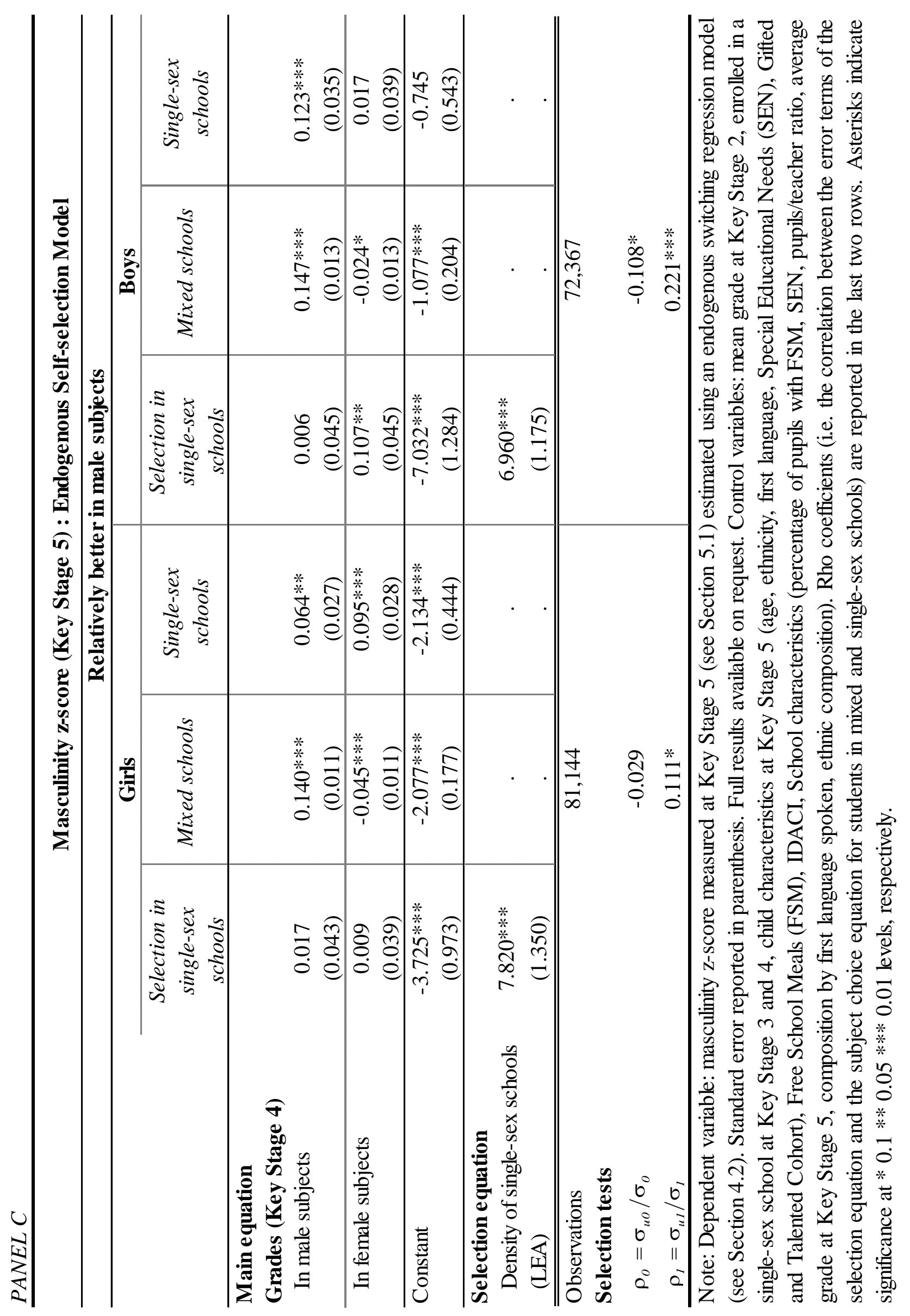


Table 10 Subject Choice at Key Stage 4: Boys versus Girls Choice of English and Mathematics

Masculinity z-score (Key Stage 4): OLS with Fixed Effect at School Level

\begin{tabular}{|c|c|c|c|c|}
\hline & \multicolumn{2}{|c|}{ Relatively better in English } & \multicolumn{2}{|c|}{$\begin{array}{l}\text { Relatively better in } \\
\text { Mathematics }\end{array}$} \\
\hline & Girls & Boys & Girls & Boys \\
\hline \multicolumn{5}{|l|}{ Grades (Key Stage 2) } \\
\hline Mathematics & $\begin{array}{l}0.002 * * * \\
(0.000)\end{array}$ & $\begin{array}{c}0.000 \\
(0.000)\end{array}$ & $\begin{array}{c}0.005 * * * \\
(0.000)\end{array}$ & $\begin{array}{c}0.007 * * * \\
(0.000)\end{array}$ \\
\hline English & $\begin{array}{c}-0.004 * * * \\
(0.001)\end{array}$ & $\begin{array}{c}-0.003 * * * \\
(0.001)\end{array}$ & $\begin{array}{c}-0.005^{* * *} \\
(0.000)\end{array}$ & $\begin{array}{c}-0.006 * * * \\
(0.000)\end{array}$ \\
\hline Constant & $\begin{array}{c}-2.194 * * * \\
(0.116)\end{array}$ & $\begin{array}{c}-1.386^{* * * *} \\
(0.132)\end{array}$ & $\begin{array}{c}-2.355^{* * *} \\
(0.116)\end{array}$ & $\begin{array}{c}-1.550^{* * * *} \\
(0.129)\end{array}$ \\
\hline Adj. R-squared & 0.18 & 0.21 & 0.18 & 0.21 \\
\hline Observations & 154,879 & 134,498 & 154,879 & 134,498 \\
\hline
\end{tabular}

Note: Dependent variable: masculinity z-score measured at Key Stage 4 (see Section 5.1), estimated using OLS with fixed effects at school level. The results correspond to the estimation of the masculinity z-score respectively for girls (equation 4) and for boys (equation 5). The grades in Mathematics and English (measured at Key Stage 2) corresponds respectively to the mgrade and the fgrade. They score from 0 to 100. Standard error accounts school-level clustering (reported in parenthesis). Asterisks indicate significance at $* 0.1 * * 0.05 * * * 0.01$ levels, respectively. Full results reported in Table B4, Appendix B. Control variables: enrolled in a single-sex school at Key Stage 3, child characteristics at Key Stage 4 (age, ethnicity, first language, Special Educational Needs (SEN), Gifted and Talented Cohort), Free School Meals (FSM), IDACI. 
Table 11 Subject Choice at Key Stage 5 Is Predetermined at Key Stage 2?

Masculinity z-score (Key Stage 5): OLS with Fixed Effect at School Level

\begin{tabular}{lc|c|c|c}
\hline & \multicolumn{2}{c|}{ Relatively better in English } & \multicolumn{2}{c}{$\begin{array}{c}\text { Relatively better in } \\
\text { Mathematics } \\
\text { Girls }\end{array}$} \\
\cline { 3 - 5 } Grades (Key Stage 2) & & Boys & & \\
Mathematics & $0.004 * * *$ & $-0.006 * * *$ & $0.028 * * *$ & $0.031 * * *$ \\
& $(0.001)$ & $(0.001)$ & $(0.000)$ & $(0.000)$ \\
English & $-0.012 * * *$ & -0.001 & $-0.025 * * *$ & $-0.025^{* * *}$ \\
& $(0.001)$ & $(0.001)$ & $(0.001)$ & $(0.000)$ \\
\hline Constant & $-0.570 * * *$ & $0.980^{* * *}$ & $-1.290^{* * *}$ & $0.229 *$ \\
& $(0.118)$ & $(0.134)$ & $(0.115)$ & $(0.125)$ \\
Adj. R-squared & 0.13 & 0.15 & 0.13 & 0.15 \\
Observations & 141,301 & 120,957 & 141,301 & 120,957 \\
\hline
\end{tabular}

Note: Dependent variable: masculinity z-score measured at Key Stage 5 (see Section 5.1), estimated using OLS with fixed effects at school level. The results correspond to the estimation of the masculinity z-score respectively for girls (equation 4) and for boys (equation 5). The grades in Mathematics and English (at Key Stage 2) corresponds respectively to the mgrade and the fgrade. They score from 0 to 100. Standard error accounts school-level clustering (reported in parenthesis). Asterisks indicate significance at * $0.1 * * 0.05 * * * 0.01$ levels, respectively. Full results available on request. Control variables: mean grade at Key Stage 2, enrolled in a single-sex school at Key Stage 3, 4 and 5, child characteristics at Key Stage 5 (age, ethnicity, first language, Special Educational Needs (SEN), Gifted and Talented Cohort), Free School Meals (FSM)), IDACI. 


\section{References}

Akerlof, G.A. 1997. "Social distance and social decisions." Econometrica 65 (5):10051027.

Akerlof, G.A. and R.E. Kranton. 2000. "Economics and identity." Quarterly journal of Economics 115 (3):715-753.

—. 2002. "Identity and schooling: some lessons for the economics of education." Journal of Economic Literature 40 (4):1167-1201.

- 2005. "Identity and the economics of organizations." The Journal of Economic Perspectives 19 (1):9-32.

Arcidiacono, P. 2004. "Ability sorting and the returns to college major." Journal of Econometrics 121 (1-2):343-375.

Becker, G. 1964. "Human capital. A theoretical and empirical analysis with special reference to education." Chicago: University of Chicago Press .

Ben-Porath, Y. 1967. "The production of human capital and the life cycle of earnings." The Journal of Political Economy 75 (4):352-365.

Bénabou, R. and J. Tirole. 2011. "Identity, morals, and taboos: beliefs as assets." The Quarterly Journal of Economics 126 (2):805-855.

Benjamin, D.J., J.J. Choi, and A.J. Strickland. 2010. "Social identity and preferences." The American economic review 100 (4):1913.

Billger, S.M. 2002. "Admitting men into a women's college: a natural experiment." Applied Economics Letters 9 (7):479-483.

Booth, A., L. Cardona, and P. Nolen. 2011. "Gender differences in risk aversion: do single-sex environments affect their development?" Mimeo .

Booth, A. and P. Nolen. 2011. "Choosing to compete: how different are girls and boys?" Journal of Economic Behavior $\&$ Organization 81 (2):542-555.

Booth, A.L. and P. Nolen. 2012. "Gender differences in risk behaviour: does nurture matter?" The Economic Journal 122 (558):F56-F78. 
Brown, C. and M. Corcoran. 1997. "Sex based differences in school content and the male-female wage gap." Journal of Labor Economics 15 (3):431-465.

Charness, G., L. Rigotti, and A. Rustichini. 2007. "Individual behavior and group membership." The American Economic Review 97 (4):1340-1352.

Chen, Y. and S.X. Li. 2009. "Group identity and social preferences." The American Economic Review 99 (1):431-457.

Cialdini Robert, B. 1993. "Influence: science and practice." New York, NY: Harper Collins .

Cont, R. and M. Löwe. 2010. "Social distance, heterogeneity and social interactions." Journal of Mathematical Economics 46 (4):572-590.

Cooley, J. 2007. "Desegregation and the achievement gap: do diverse peers help?" Unpublished manuscript, University of Wisconsin-Madison .

Croson, R. and U. Gneezy. 2009. "Gender differences in preferences." Journal of Economic Literature 47 (2):448-474.

Cunha, F. and J.J. Heckman. 2007. "Identifying and estimating the distributions of ex post and ex ante returns to schooling." Labour Economics 14 (6):870-893.

Dee, T.S. 2007. "Teachers and the gender gaps in student achievement." Journal of Human Resources 42 (3):528-554.

Delavande, A. and B. Zafar. 2011. "Stereotypes and Madrassas: Experimental Evidence from Pakistan." FRB of New York Staff Report No. 501.

Francis, B. 2000. "The gendered subject: students' subject preferences and discussions of gender and subject ability." Oxford Review of Education 26 (1):35-48.

Gneezy, U., K.L. Leonard, and A.J. List. 2009. "Gender differences in competition: evidence from a matrilineal and a patriarchal society." Econometrica 77 (5):1637-1664.

Gneezy, U., M. Niederle, and A. Rustichini. 2003. "Performance in competitive environments: gender differences." Quarterly Journal of Economics 118 (3):1049-1074. 
Gneezy, U. and A. Rustichini. 2004. "Gender and competition at a young age." The American Economic Review 94 (2):377-381.

Gronau, R. 1974. "Wage comparisons-a selectivity bias." Journal of Political Economy 81:1119-1143.

Grotevant, H.D. 1987. "Toward a process model of identity formation." Journal of adolescent research 2 (3):203.

Gupta, N.D., A. Poulsen, and M.C. Villeval. 2005. "Male and female competitive behavior: experimental evidence." IZA Discussion Paper (1833).

Haag, P. 2000. K-12 single-sex education: what does the research say? ERIC Clearinghouse on Elementary and Early Childhood Education, University of Illinois.

Heckman, J. 1974. "Shadow prices, market wages, and labor supply." Econometrica: Journal of the Econometric Society :679-694.

Hoff, K. and P. Pandey. 2006. "Discrimination, social identity, and durable inequalities." The American economic review 96 (2):206-211.

Humlum, M.K., K.J. Kleinjans, and H.S. Nielsen. 2012. "An economic analysis of identity and career choice." Economic Inquiry 50 (1):39-61.

Jackson, C.K. 2012. "Single-sex schools, student achievement, and course selection: evidence from rule-based student assignments in Trinidad and Tobago." Journal of Public Economics 96 (1-2):173-187.

Jackson, M.O. 2009. Social and economic networks. Princeton University Press.

Joshi, H., D. Leonard, and A. Sullivan. 2010. "Single-sex Schooling and Academic Attainment at School and through the Lifecourse." American Educational Research Journal 47 (1):6-36.

Kanter, R.M. 1977. "Some effects of proportions on group life: skewed sex ratios and responses to token women." American journal of Sociology 82 (5):965-990.

Killgore, W.D.S. and D.A. Yurgelun-Todd. 2004. "Sex related developmental differences in the lateralized activation of the prefrontal cortex and the amygdala during the perception of facial affect." Perceptual and motor skills 99 (2):371-391. 
Kimura, D. 2000. Sex and cognition. The MIT Press.

Kurtz-Costes, B., S.J. Rowley, A. Harris-Britt, and T.A. Woods. 2008. "Gender stereotypes about mathematics and science and self-perceptions of ability in late childhood and early adolescence." Merrill-Palmer Quarterly 54 (3):386-409.

Lee, V.E., H.M. Marks, and T. Byrd. 1994. "Sexism in single-sex and coeducational independent secondary school classrooms." Sociology of Education 67 (2):92-120.

Lenroot, R.K., N. Gogtay, D.K. Greenstein, E.M. Wells, G.L. Wallace, L.S. Clasen, J.D. Blumenthal, J. Lerch, A.P. Zijdenbos, A.C. Evans et al. 2007. "Sexual dimorphism of brain developmental trajectories during childhood and adolescence." Neuroimage 36 (4):1065-1073.

Levine, J.M. 1989. "Reaction to opinion deviance in small groups." Lawrence Erlbaum Associates, Inc.

Lewis, H.G. 1974. "Comments on selectivity biases in wage comparisons." The Journal of Political Economy 82 (6):1145-1155.

Lokshin, M. and Z. Sajaia. 2004. "Maximum likelihood estimation of endogenous switching regression models." Stata Journal 4:282-289.

Maddala, G.S. 1983. Limited-dependent and qualitative variables in econometrics, vol. 3. Cambridge University Press.

Mael, F., A. Alonso, D. Gibson, K. Rogers, and M. Smith. 2005. "Single-sex versus coeducational schooling: a systematic review." US Department of Education Doc. 2005$01: 148$

Manski, C.F. 2000. "Economic analysis of social interactions." The Journal of Economic Perspectives 14 (3):115-136.

Marsden, P.V. 1988. "Homogeneity in confiding relations." Social Networks 10 (1):57-76.

Mincer, J. 1974. "Schooling, experience, and earnings." New York: Columbia University Press . 
Mokhtarian, P.L. and X. Cao. 2008. "Examining the impacts of residential self-selection on travel behavior: a focus on methodologies." Transportation Research Part B: Methodological $42(3): 204-228$.

Niederle, M and Vesterlund L. 2007. "Do women shy away from competition? Do men compete too much?" Quarterly Journal of Economics 122 (3):1067-1101.

Niederle, M. and L. Vesterlund. 2010. "Explaining the gender gap in math test scores: the role of competition." The Journal of Economic Perspectives 24 (2):129-144.

Noe, C. 2010. "Family background and female's choice of male's subjects: evidence from Italy." ChilD Working Paper n.01.

Oakes, J. 1990. "Opportunities, achievement, and choice: Women and minority students in science and mathematics." Review of research in education 16:153-222.

O’Donoghue, T. and M. Rabin. 1999. "Doing it now or later." American Economic Review 89 (01):103-124.

Park, H. and J.R. Behrman. 2012. "Causal effects of single-sex schools on college attendance: random assignment in Korean high schools." PSC Working Paper Series, forthcoming in Demography 10 (01).

Pomerantz, E.M., E.R. Altermatt, and J.L. Saxon. 2002. "Making the grade but feeling distressed: gender differences in academic performance and internal distress." Journal of Educational Psychology 94 (2):396.

Quandt, R. 1972. "Methods for estimating switching regressions." Journal of the American Statistical Association 67 (338):306-310.

Riordan, C.H. 2002. "Girls and boys in school: together or separate?" American Journal of Sociology 96 (5):1292-1294.

Rogers, S.J. and E.G. Menaghan. 1991. "Women's persistence in undergraduate majors: the effects of gender-disproportionate representation." Gender and Society 5 (4):549-564.

Roy, A.D. 1951. "Some thoughts on the distribution of earnings." Oxford Economic Papers 3 (2):135-146. 
Sacerdote, B. 2001. "Peer effects with random assignment: results for Dartmouth roommates." Quarterly Journal of Economics 116 (2):681-704.

Schneeweis, N. and M. Zweimüller. 2012. "Girls, girls, girls: gender composition and female school choice." Economics of Education Review 31 (4):482-500.

Schultz, T.W. 1963. "The economic value of education." Columbia University Press New York 63.

Shamai, S. 1994. "Possibilities and limitations of a gender stereotypes intervention program." Adolescence 29 (115):665-80.

Stables, A. 1990. "Differences between pupils from mixed and single-sex schools in their enjoyment of school subjects and in their attitudes to science and to school." Educational Review 42 (3):221-230.

Staw, B.M. 1976. "Knee-deep in the big muddy: a study of escalating commitment to a chosen course of action." Organizational Behavior and Human Performance 16 (1):2744.

Streitmatter, J. 2002. "Perceptions of a single-sex class experience: females and males see it differently." In A. Datnow and L. Hubbard (Eds.), Gender in policy and practice: Perspectives on single-sex and coeducational schooling :212-226.

Sutter, M. and D. Rützler. 2010. "Gender differences in competition emerge early in life." IZA Discussion Paper (n.5015).

Tajfel, H. and J.C. Turner. 1979. "An integrative theory of intergroup conflict." In $W$. G. Austin and S. Worchel (Eds.), The Social Psychology of Intergroup Relations :33-47.

Tidball, M.E. 1985. "Baccalaureate origins of entrants into American medical schools." The Journal of Higher Education 56 (4):385-402.

- 1986. "Baccalaureate origins of recent natural science doctorates." The Journal of Higher Education 57 (6):606-620.

Turner, J.C. 1991. Social influence. Thomson Brooks/Cole Publishing Co. 
Turner, S.E. and W.G. Bowen. 1999. "Choice of major: the changing (unchanging) gender gap." Industrial and Labor Relations Review 52 (2):289-313.

Van De Werfhorst, H.G., A. Sullivan, and S.Y. Cheung. 2003. "Social class, ability and choice of subject in secondary and tertiary education in Britain." British Educational Research Journal 29 (1):41-62.

Wikeley, F. and A. Stables. 1999. "Changes in school students' approaches to subject option choices: a study of pupils in the West of England in 1984 and 1996." Educational Research 41 (3):287-299.

Wilder, G.Z., K. Powell, and College Entrance Examination Board. 1989. "Sex differences in test performance: a survey of literature." College Entrance Examination Board New York .

Wooldridge, J.M. 2002. Econometric analysis of cross section and panel data. The MIT press.

Zafar, B. 2009. "College major choice and the gender gap." FRB of New York Staff Report No.364.

- 2011(a). "How do college students form expectations?" Journal of Labor Economics 29 (2):301-348.

_. 2011(b). "An experimental investigation of why individuals conform." European Economic Review 55 (6):774-798.

_ 2011(c). "Can subjective expectations data be used in choice models? evidence on cognitive biases." Journal of Applied Econometrics 26 (3):520-544. 


\section{Appendix A}

\section{A.1 Control variables}

\begin{tabular}{|c|c|}
\hline Grades & $\begin{array}{l}\text { Key Stage } 2 \text { and Key Stage } 3 \text { average grades } \\
\text { in National Curriculum assessments in } \\
\text { English, Math and Science. }\end{array}$ \\
\hline Single-sex schools & $\begin{array}{l}\text { Have studied in a single-sex school at Key } \\
\text { Stage } 3 \text { and } 4 \text { and being enrolled in a single- } \\
\text { sex school during Key Stage } 5 .\end{array}$ \\
\hline \multicolumn{2}{|l|}{ Child characteristics } \\
\hline Age & In years \\
\hline Ethnicity & $\begin{array}{l}\text { White, Bangladeshi/Pakistani, Indian, } \\
\text { Chinese, Black African and Black Caribbean }\end{array}$ \\
\hline Special Educational Needs (SEN) & $\begin{array}{l}\text { Dummy equal to } 1 \text { if he/she is received (at } \\
\text { least once during Key Stage 5) a statement } \\
\text { for SEN. The Education Act } 1996 \text { says that } \\
\text { "a child has special educational needs if he } \\
\text { or she has a learning difficulty which calls } \\
\text { for special educational provision to be made } \\
\text { for him or her" }\end{array}$ \\
\hline Gifted and Talent cohort & $\begin{array}{l}\text { Dummy equal to } 1 \text { if he/she is included in the } \\
\text { Gifted and Talent cohort. It includes those } \\
\text { students who have one or more abilities } \\
\text { developed to a level significantly ahead of } \\
\text { their year group. }\end{array}$ \\
\hline Migration background & $\begin{array}{l}\text { Dummy equal to } 1 \text { if English is the first } \\
\text { language }\end{array}$ \\
\hline \multicolumn{2}{|l|}{ Socio-economic status } \\
\hline Free School Meals (FSM) & $\begin{array}{l}\text { Dummy equal to } 1 \text { if the child has received a } \\
\text { statements for FSM during the same Key } \\
\text { Stage }\end{array}$ \\
\hline \multicolumn{2}{|l|}{ Neighbourhood characteristics } \\
\hline IDACI score & $\begin{array}{l}\text { The IDACI shows the percentage of children } \\
\text { in each of the Super Output Area (SOA) that } \\
\text { live in families that are income deprived (i.e., }\end{array}$ \\
\hline
\end{tabular}




\begin{tabular}{|c|c|}
\hline & $\begin{array}{l}\text { in receipt of Income Support, Income based } \\
\text { Jobseeker's Allowance, Working Families' } \\
\text { Tax Credit or Disabled Person's Tax Credit } \\
\text { below a given threshold). An IDACI score of } \\
0.24 \text { means that } 24 \% \text { of children aged less } \\
\text { than } 16 \text { in that SOA are living in families that } \\
\text { are income deprived. The postcodes of pupils } \\
\text { are used to gain the IDACI scores for each } \\
\text { pupil within each school using the SOAs. } \\
\text { The average score for each school (total of all } \\
\text { pupils IDACI Score based on postcode } \\
\text { divided by the total number of pupils) is then } \\
\text { compared to the national } 32,482 \text { SOAs } \\
\text { percentile rank. This then gives the school a } \\
\text { national ranking based on the pupils within } \\
\text { their } \\
\text { (http://www.education.gov.uk/cgi- } \\
\text { bin/inyourarea/idaci.pl). }\end{array}$ \\
\hline \multicolumn{2}{|l|}{ School characteristics } \\
\hline \multirow[t]{2}{*}{ School quality } & $\begin{array}{l}\text { Pupils/teacher ratio at school level, during } \\
\text { Key Stage } 5\end{array}$ \\
\hline & $\begin{array}{l}\text { Average grade achieved at Key Stage } 5 \text {, at } \\
\text { school level }\end{array}$ \\
\hline \multirow[t]{2}{*}{ Ethnic composition } & $\begin{array}{l}\text { Percentage of White, Bangladeshi/Pakistani, } \\
\text { Indian, Chinese, Black African and Black } \\
\text { Caribbean at school level }\end{array}$ \\
\hline & $\begin{array}{l}\text { Percentage of students for which English is } \\
\text { not the first language }\end{array}$ \\
\hline Gender composition & Percentage of male students at school level \\
\hline \multirow[t]{2}{*}{ Others variables at school level } & Percentage of students with $F S M$ \\
\hline & Percentage of students with $S E N$ \\
\hline
\end{tabular}




\section{A2. English educational system}

The English educational system is divided in primary education, compulsory secondary education and post-compulsory secondary education as showed in the figure below. After secondary education students may apply to higher education institutions/universities.

English educational system

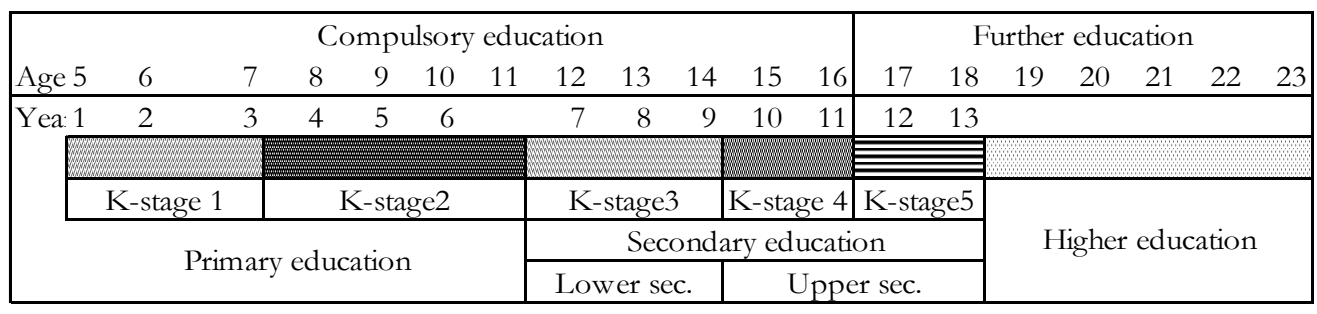

In England, education is mainly provided by maintained schools (i.e. public schools, including community schools, foundation schools, voluntary aided schools and voluntary controlled schools.), while 7 percent of the school age population enrol in independent schools (private schools). In general, no charge may be made for education provided for pupils in maintained schools. Conversely, most independent schools are financed by means of fees paid by parents or donations and grants received from benefactors.

The primary school lasts 7 seven years and comprises 2 Key stages, Key Stage 1 and Key Stage 2 (pupils aged five to seven, and seven to 11, respectively). In these two Key Stages all students study three compulsory/core subjects: English, Mathematics, Science plus some core subjects. After primary education, students accede to secondary education. The first five years of secondary education (pupils aged 11 to 16 years of age) fall within the period of compulsory education and the last two years of post-compulsory full-time secondary education are usually denominated sixth-form. The compulsory secondary education is divided into two key stages, Key Stage 3 for pupils aged 11-14 years and Key Stage 4 for those aged 14-16 years. After that, students may decide either to leave education or follow in post-compulsory secondary education provided for pupils aged 16 to 18 years.

Key Stage 3 is commonly known as lower-secondary education and Key Stage 4 and Key Stages 5 as upper-secondary education. During upper-secondary education students may choose subjects leading to academic or vocational certificates. Vocational qualifications are intended to offer a comprehensive preparation for employment, as well as a route to higherlevel qualifications. Generally, those students studying vocational subjects at Key Stage 4 are 
more likely to drop out of school at the end of compulsory education, although Key Stage 5 offers a wide range of vocational subjects. Those students choosing a more academic curriculum are more likely to go to post-compulsory education and higher education.

At the end of Key Stage 3 students take National Curriculum tests in English, Mathematics and Science. Assessment of pupils at Key Stage 4 is normally by the General Certificate of Secondary Education (GCSE) which consists of a range of examinations in single subjects. A certificate is issued listing the grade which a candidate has achieved in each subject attempted. The results are reported on an eight-point scale: A*, A, B, C, D, E, F and U. Candidates who fail to reach the minimum standard for grade $F$ are recorded as ' $U$ ' for 'unclassified' and do not receive a certificate. In June 2008, the Secretary of State for Children, Schools and Families launched the National Challenge. This is a programme of support to secure higher standards in all secondary schools so that, by 2011 , at least 30 per cent of pupils in every school will gain five or more GCSEs at grades $\mathrm{A} *$ to $\mathrm{C}$, including both English and Mathematics.

Since 2002 General Certificates of Secondary Education in vocational or applied subjects (GCSEs) have been available. Applied GCSEs were previously known as General National Vocational Qualifications (GNVQs), which were withdrawn gradually between 2005 and 2007. During Key Stage 5, students may take a number of courses leading to approved qualifications, including General Certificate of Education Advanced-level (GCE A-level), GCE Advanced Subsidiary (GCE applied AS level) and A-levels in applied subjects (GCE applied A-level). All these qualifications are acceptable for entry into higher education. Note that, GCE in applied subjects ( $A$ and AS levels) were previously called Vocational Certificate of Education ( $A$ and AS levels). These qualifications phased out during the academic year $2007 / 2008$ and were replaced by the new qualifications from 2008/2009 onwards. In the present analysis students studying for vocational qualifications have been excluded.

Most secondary schools which are maintained schools are non-selective and accept pupils regardless of ability. These are known as comprehensive schools. In some areas of England, there are also schools which select their pupils by ability and are commonly known as grammar schools. Additionally, there are no official qualifications required for admission to the sixth-form of a secondary school, but schools generally set their own admission requirements. Schools commonly ask for a minimum of five GCSE passes at grades $\mathrm{A}^{*}-\mathrm{C}$ 
for admission to GCE A-level courses. Criteria for admission to GCE A-level courses often include the achievement of good GCSE passes (usually grade $\mathrm{C}$ or above) in the subjects to be studied at GCE A-level. 